Miriam Cardoso Neves Eller

\title{
Avaliação do perfil inflamatório dos pacientes pediátricos com asma grave e sua correlação com o controle da doença e parâmetros funcionais
}

\author{
Dissertação apresentada à Faculdade de Medicina \\ da Universidade de São Paulo para obtenção do \\ título de Mestre em Ciências \\ Programa de Pediatria \\ Orientador: Prof. Dr. Joaquim Carlos Rodrigues
}

(Versão corrigida. Resolução CoPGr 5890, de 20 de dezembro de 2010.

A versão original está disponível na Biblioteca FMUSP)

\section{São Paulo}


Esta dissertação está de acordo com as seguintes normas, em vigor no momento desta publicação:

Universidade de São Paulo. Faculdade de Medicina. Divisão de Biblioteca e Documentação. Guia de apresentação de dissertações, teses e monografas. Elaborado por Anneliese Carneiro da Cunha, Maria Julia de A. L. Freddi, Maria F. Crestana, Marinalva de Souza Aragão, Suely Campos Cardoso, Valéria Vilhena. 3a ed. São Paulo: Divisão de Biblioteca e Documentação; 2011. Referências: adaptado de International Committee of Medical Journals Editors (Vancouver). 
Aos meus amores:

Estêvão, Francisco e Thomas 


\section{AGRADECIMENTOS}

Agradeço a Deus, Criador e Soberano, pela dádiva da vida e sustento.

Ao Dr. Joaquim Carlos Rodrigues, que foi um verdadeiro mestre, não se limitou apenas ao papel de orientador, mas compartilhou seu conhecimento sempre com muita disposição e simpatia.

Ao Estevão Eller, meu esposo e parceiro de todas as horas. Sem você, não seria possível. Obrigada pela ajuda imprescindível com as planilhas do Excel, por cuidar tão bem dos nossos filhos e de mim, por ser meu maior incentivador e acreditar em mim as vezes mais do que eu mesma.

À querida amiga Karina P. Vergani. Formamos uma ótima dupla! Graças a sua parceria foi possível a realização deste projeto.

Ao prof. Milton de Arruda Martins pela colaboração e Beatriz Saraiva-Romanholo pelo treinamento no processamento do escarro e leitura das lâminas e também pela amizade.

À Dra. Leila Antonangelo e Caroline Faria pela colaboração na dosagem das citocinas.

Às técnicas do laboratório de função de pulmonar: Maria Inês e Claudia Xavier pela realização dos exames sempre com disposição e alegria.

Ao Prof. Claudio Leone pelo auxílio no projeto e análise estatística.

À equipe da gastroenterologia pediátrica do Instituto da Criança, em especial a Dra. Mariana Deboni, pela colaboração no estudo.

Ao Dr. Fabio Pina, otorrinolaringologista, pela cordial contribuição na avaliação dos pacientes.

A toda equipe da Pneumologia do Instituto da Criança do Hospital das Clínicas da FMUSP, em especial Dr. Luiz Vicente, Dra Fabiola Adde, Dra. Cleyde Myriam Nakaie, Dra. Marina B. de Almeida e Dr. Fabio Muchão pelo acolhimento, apoio e ensinamentos durante minha jornada.

Aos meus pais, Jaime Neves e Maria de Fátima Neves, por serem o alicerce do que sou hoje.

Aos pacientes, que motivaram a realização deste projeto, e seus pais que participaram desde estudo com empenho e boa vontade. 


\section{AGRADECIMENTOS}

À FAPESP (Fundação de Amparo à Pesquisa do Estado de São Paulo) pelo apoio financeiro a este trabalho científico.

À CAPES pela bolsa de estudos. 


\section{SUMÁRIO}

\section{Resumo}

\section{Abstract}

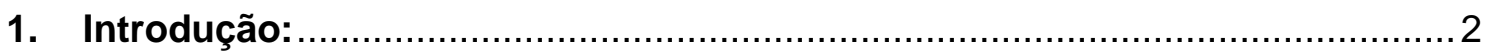

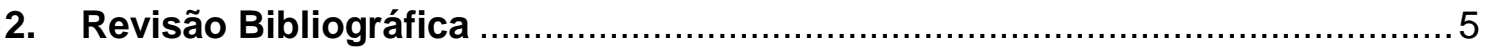

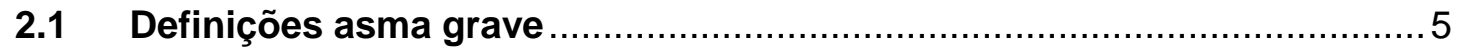

2.1.1 Definição asma grave pelo GINA ............................................... 5

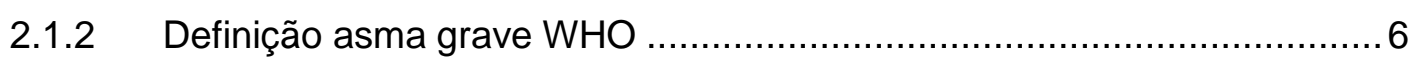

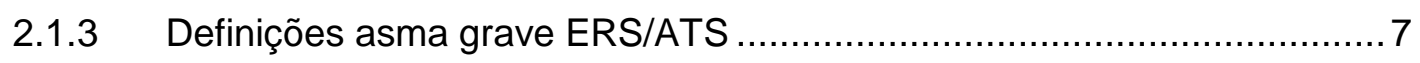

2.2 Avaliação do fenótipo inflamatório: ................................................. 9

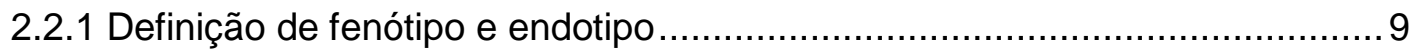

2.2.2 Métodos para avaliação dos fenótipos inflamatórios: ................................10

2.2.3 Células inflamatórias..................................................................... 14

2.3. Correlação do fenótipo inflamatório com parâmetros funcionais: .........17

2.4 Paradigma da resposta imune................................................................ 18

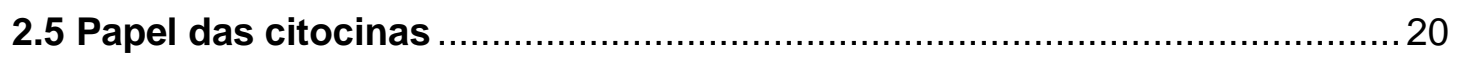

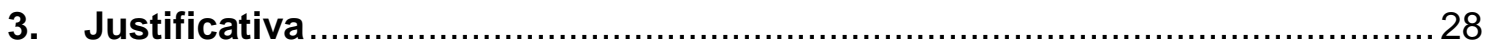

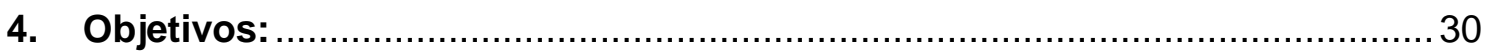

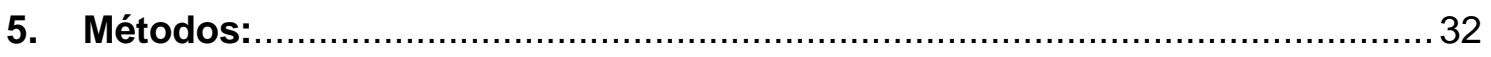

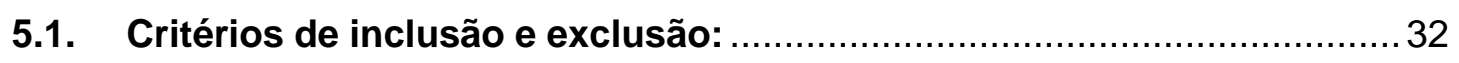

5.2. Desenho do estudo ..................................................................... 33

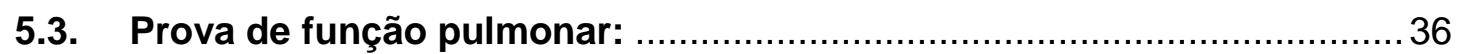

5.4. Medida da fração expirada de óxido nítrico: ......................................... 37

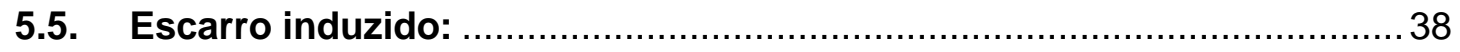

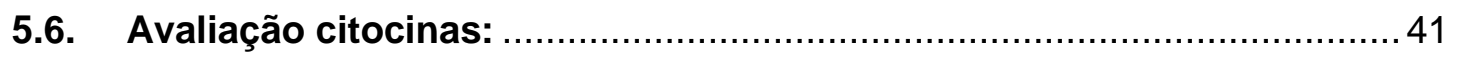

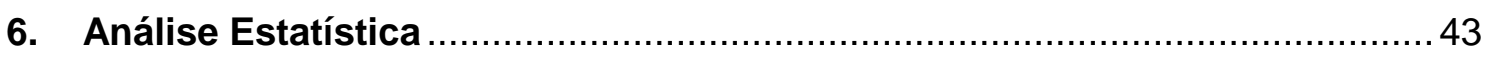

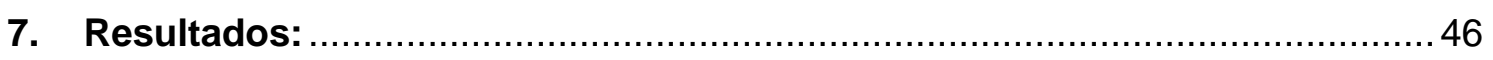

7.1. Dados demográficos e clínicos: ......................................................... 46

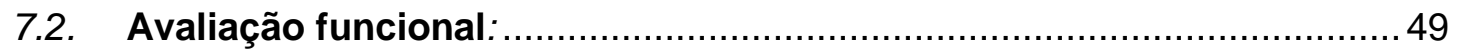

7.3. Marcadores inflamatórios séricos, FeNO e Escarro induzido: ................50 


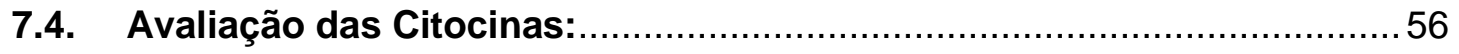

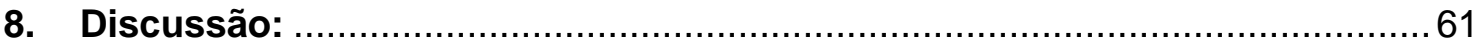

8.1 Caracterização da casuística utilizada.................................................... 61

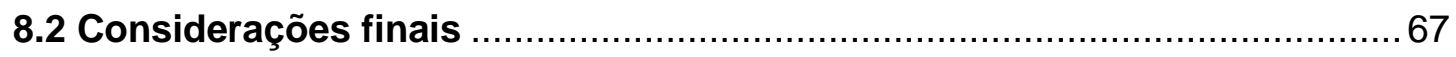

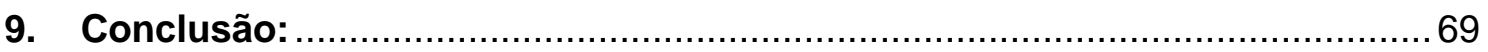

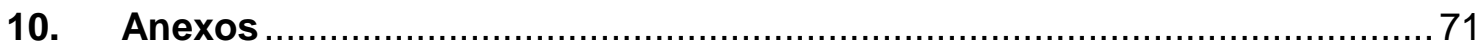

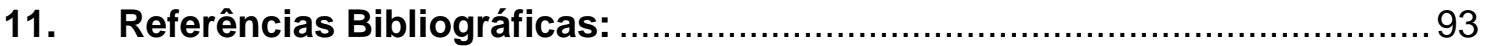




\section{Resumo}

Introdução: Os mecanismos fisiopatológicos da asma grave resistente ao tratamento (AGRT) em crianças não está totalmente elucidado e parece diferir do observado em adultos, justificando investigações específicas neste grupo de pacientes. O escarro induzido é método útil para identificar fenótipos e endotipos de asma grave através de marcadores inflamatórios. O objetivo deste estudo foi investigar os padrões inflamatórios de crianças com AGRT através escarro induzido e comparar com um grupo de crianças com asma grave que atingiram o controle. Métodos: Crianças (6-18 anos) com diagnóstico de asma grave (critério GINA) em tratamento a pelo menos 6 meses em um centro de referência foram avaliadas em um coorte prospectivo por 3 meses (3 visitas consecutivas). Foi averiguada técnica inalatória, adesão ao tratamento e investigado as principais comorbidades. Realizado coleta de escarro induzido para análise citológica e avaliação quantitativa de citocinas do sobrenadante, espirometria, pletismografia e medidas da FeNO. Após período de seguimento, os pacientes foram classificados em dois grupos: asma grave controlada e asma grave resistente ao tratamento conforme critérios da ATS/ERS. Resultados: Foram incluídos 40 pacientes (idade média 12,8 anos; $62,5 \%$ sexo masculino), sendo $13(32,5 \%)$ classificados como AGRT após o período de seguimento. A mediana do número de exacerbações foi maior e do escore de ACT menor nos pacientes AGRT e esta diferença foi significativa. Não foram encontradas diferenças 
significativas: nos dados demográficos, nos parâmetros funcionais espirométricos e de pletismografia (CVF, VEF1, VEF/CV, FEF 25-75\%, LTC, RV, RV/LTC, resistência e condutância das vias aéreas) e nos valores de FeNO quando comparado o grupo de pacientes controlados com o de AGRT. O padrão inflamatório eosinofílico foi predominante nos dois grupos de pacientes, entretanto, o grupo AGRT apresentou porcentagem proporcionalmente maior de neutrófilos no escarro comparados com o grupo de asma grave controlada, na visita 3 e também na visita 1 quando analisados retrospectivamente $(p<0,05)$. As medianas nos níveis das citocinas IL10, GM-CSF, INFy e TNFa no escarro foram significativamente maiores no grupo AGRT quando comparado ao grupo controlado $(p<0,05)$ e o GM-CSF e TNF- $\alpha$ apresentaram correlação inversa com escore de ACT. Conclusão: Nesta coorte prospectiva, os parâmetros funcionais e a FeNO não discriminaram crianças com STRA dos que atingiram o controle. A presença de neutrófilos no escarro e das citocinas IL10, INFY e, particularmente, GM-CSF e TNFa podem ser biomarcadores de asma grave resistente ao tratamento em crianças e adolescentes. Antagonistas específicos dessas citocinas podem no futuro representar uma estratégia na terapêutica. 


\section{Abstract}

Background: The pathophysiological mechanisms of severe therapyresistant asthma (STRA) in children are not fully elucidated and seem to differ from findings in adults, thus justifying specific research on children. Induced sputum is useful for detecting phenotypes and endotypes of severe asthma via inflammatory markers. The aim of the present study was to investigate the inflammatory patterns of children with STRA by the induced sputum method and to compare them with a group of children who achieved control of severe asthma. Methods: A prospective cohort of children (6-18 years old) diagnosed with severe asthma (Global Initiative for Asthma - GINA criteria) and in treatment for at least 6 months at a reference center was assessed for 3 months ( 3 consecutive visits). Inhalation technique, adherence to treatment and main comorbidities were assessed. Induced sputum samples were collected for cytology analysis and quantitative assessment of cytokines in the supernatant; the participants were also subjected to spirometry, plethysmography and fractional exhaled nitric oxide (FeNO) measurements. At the end of follow-up, the patients were classified into two groups: controlled severe asthma and STRA according to the European Respiratory Society and American Thoracic Society (ERS/ATS) criteria. Results: Forty patients were included (average age 12.8 years old; $62.5 \%$ male); 13 (32.5\%) were classified as STRA at the end of follow up. The median number of exacerbations was higher and the Asthma Control Test (ACT) score was lower in 
the STRA group; these differences were significant. Significant differences were not found relative to demographic data, spirometry and plethysmography function parameters [forced vital capacity (FVC), forced expiratory volume in the first second (FEV1), ratio of FEV1 to slow vital capacity (FEV1/SCV), forced expiratory flow at $25-75 \%$ of FVC (FEF $25-75 \%$ ), total lung capacity (TLC), residual volume $(\mathrm{RV}), \mathrm{RV} / \mathrm{TLC}$, airway resistance and conductance] and FeNO after comparison of the STRA and controlled asthma groups. The eosinophilic inflammatory pattern predominated in both groups; however, the STRA group showed a proportionally higher percentage of sputum neutrophils compared with the controlled asthma group at visit 3 and visit 1 upon retrospective analysis $(p<0.05)$. The median sputum levels of the cytokines IL-10, GM-CSF, IFN- $y$ and TNF- $\alpha$ were significantly higher in the STRA group compared with the controlled asthma group $(\mathrm{p}<0.05)$; GM-CSF and TNF- $\alpha$ showed inverse correlations with ACT scores. Conclusion: In the analyzed prospective cohort, functional parameters and FeNO did not discriminate between children with STRA and children with controlled asthma. The presence of neutrophils and the cytokines IL-10, IFN- $y$ and, more particularly, TNF- $\alpha$ and GM-CSF in the sputum might have a role in resistance to treatment for severe asthma among children and adolescents. Antagonists specific for these cytokines might represent a therapeutic strategy in the future. 
1 INTRODUÇÃO 


\section{Introdução}

A asma é uma doença crônica de alta prevalência na infância e adolescência e é considerada por muitos autores como uma síndrome de caráter heterogêneo cujas manifestações resultam de uma interação extremamente complexa entre fatores genéticos e ambientais ${ }^{1}$.

A prevalência de asma na infância na América latina varia de 4\% a 30\%. ${ }^{2}$ No estudo ISAAC (International Study of Asthma and Allergies in Childhood) - Fase 3 a prevalência média de asma ativa (sibilos nos últimos 12 meses) no Brasil foi de $24,3 \%$ (oscilando de 16,5 a $31,2 \%$ ) para crianças e de 19,0\% (oscilando de 11,8 a 30,5\%) para adolescentes; e de diagnóstico médico de asma de 10,5\% para crianças e 13,6\% para os adolescentes ${ }^{3}$. A maioria das crianças com asma tem doença leve a moderada e respondem ao tratamento com broncodilatadores de curta duração com ou sem uso contínuo de agentes anti-inflamatórios em baixa dosagem.

Entretanto, cerca de 5 a 10\% dos asmáticos não respondem favoravelmente ao tratamento preconizado pelos consensos ${ }^{4}$. Apesar da pequena proporção destes pacientes em relação ao número total de asmáticos, a sua contribuição para a morbi-mortalidade é desproporcionalmente elevada e corresponde a 40$50 \%$ dos custos em saúde com pacientes asmáticos 5 .

Os achados sobre a relação da inflamação celular e os fenótipos de asma apontam para o conceito de que diferentes subgrupos de pacientes com asma,

a despeito das características clínicas similares, podem ser diferenciados por marcadores celulares e moleculares específicos, o que poderia auxiliar em tratamentos mais individualizados ${ }^{6}$. Existe hoje um crescente interesse na 
identificação de biomarcadores fenotípicos, pois terapias biológicas com alvo nos fenótipos inflamatórios estão se mostrando cada vez mais eficazes ${ }^{7}$.

O conhecimento atual sobre os fenótipos e endotipos de asma grave na infância ainda é limitado. Embora o fenótipo de asma de início na infância seja reconhecido nos adultos, a doença na criança não é necessariamente a mesma ${ }^{8}$. Existem diferenças nos fatores que regem a doença no adulto e na criança, principalmente pela doença na criança e adolescente ocorrer no contexto de um sistema imunológico em maturação e durante o crescimento e desenvolvimento pulmonar $^{9}$, justificando novos estudos sobre a asma grave nesta população. 
2 REVISÃO BIBLIOGRÁFICA 


\section{Revisão Bibliográfica}

\subsection{Definições asma grave}

\subsubsection{Definição asma grave pela GINA}

A Global Initiative for Asthma (GINA) foi criado em 1993 pelo National Heart, Lung and Blood Institute em colaboração com a Organização Mundial da Saúde. Na primeira edição da GINA a gravidade da asma foi baseada nas características clínicas dos pacientes incluindo medidas de função pulmonar antes do início do tratamento. Com o passar do tempo foi reconhecido que a gravidade da asma deveria ser categorizada e deveria também envolver a resposta ao tratamento. Em 2005, o comitê executivo recomendou um novo documento não apenas para incorporar as novas informações cientificas, mas para a implantação do manejo da asma baseado no controle e não na gravidade da doença ${ }^{6}$.

A Gina 2009 enfatizou a classificação não mais baseada na intensidade dos sintomas (intermitente, persistente leve, moderada e grave), mas reconheceu que a gravidade da doença envolve a intensidade e a resposta ao tratamento. Além disso, a gravidade não é uma característica estática de um indivíduo com asma pois pode se modificar ao longo dos anos ${ }^{10}$. Portanto a gravidade da asma passou a ser classificada com base da intensidade de tratamento necessário para adquirir o seu controle, sendo asma grave definida como asma que requer tratamento Step 4: corticoide inalatório em dose média a 
alta associado a uma segunda medicação de controle (broncodilatador de longa ação ou antagonista de leucotrieno) e/ou corticoide sistêmico para manter controle adequado ou quando seu controle não é adquirido a despeito do tratamento de alta intensidade, após confirmação diagnóstica e identificação das comorbidades $^{6,7}$.

A mais recente edição da GINA (2017) mantém a definição de asma grave aquela que requer tratamento no Step 4 ou 5 para seu controle ou que não alcança o controle a despeito deste tratamento. Ainda recomenda que, para estudos epidemiológicos e ensaios clínicos, é preferível categorizar pacientes pelo Step de tratamento, sem inferir gravidade ${ }^{11}$.

\subsubsection{Definição asma grave WHO}

Em 2010 foi publicada uma definição de gravidade, controle e exacerbações pela Organização Mundial de Saúde (World Health Organization - WHO) na qual a gravidade, controle e responsividade ao tratamento da asma estão correlacionados. O nível de controle inclui controle clínico (frequência e intensidade de sintomas diurnos e noturnos, limitações funcionais e para atividade física, uso de medicação de resgate e função pulmonar) e número de exacerbações ${ }^{12}$.

A WHO sugere que a asma grave seja definida, pelo nível de controle clínico e risco, como asma não controlada que pode resultar em exacerbações graves frequentes (ou morte) e/ou reações adversas a medicações e/ou morbidade crônica (incluindo perda de função pulmonar ou redução de 
crescimento nas crianças) ${ }^{6}$. Quando aplicada essa definição para a população geral, a asma grave é dividida em três grupos: asma grave não tratada, asma grave de difícil tratamento/controle (devido presença de comorbidades, fatores ambientais e/ou não adesão ao tratamento) e asma grave resistente ao tratamento (incluindo asma em que o controle não pode ser alcançado a despeito do tratamento de último nível recomendado, e asma em que o controle pode ser alcançado apenas com o tratamento no mais alto nível recomendado) $)^{6,12}$.

\subsubsection{Definições asma grave ERS/ATS}

Em 1999 uma força tarefa da European Respiratory Society (ERS) definiu asma resistente ao tratamento como o pobre controle da doença com necessidade de uso contínuo de medicação de resgate a despeito do tratamento com doses altas de corticosteroides inalatórios e o seguimento de pelo menos 6 meses por especialista 5 .

A American Thoracic Society (ATS), em 2000, publicou no Proceedings of the ATS Workshop on Refractory Asthma que a "asma refratária" não se limita apenas aos pacientes com asma "fatal" ou "quase fatal", mas engloba subgrupos de asma previamente descritos como "asma grave", "asma dependente e/ou resistente aos corticosteroides", "asma de difícil controle", "asma pobremente controlada" ou "asma irreversível". Clinicamente, os pacientes com asma refratária podem apresentar uma variedade de condições que podem se sobrepor: 1) ampla variação de picos de fluxo, 2) limitação grave e crônica das vias aéreas, 3) perda rápida e progressiva de função pulmonar, 4) produção de muco variando de ausente a copiosa, 5) resposta variada aos corticosteroides ${ }^{13}$. 
Esse mesmo documento define então asma grave refrataria aquela que requer pelo menos um critério maior: tratamento com corticoide oral contínuo ou quase continuo (maior que $50 \%$ do ano) e/ou tratamento com altas doses de corticoide inalatório, e dois dos sete critérios menores. Os critérios menores incluíam: necessidade de tratamento adicional como medicação de controle, por exemplo beta2 agonista de longa ação ou antagonista de leucotrieno; sintomas de asma com necessidade de uso de beta2 agonista de curta duração diário ou quase diário; obstrução persistente de vias áreas (VEF1 < $80 \%$ predito, variabilidade de pico expiratório diurno $>20 \%$ ); uma ou mais visitas a serviço de emergência por asma por ano; três ou mais cursos de corticoide oral por ano; deterioração rápida após redução de $25 \%$ ou menos na dose de corticoide oral ou inalatório; um evento quase fatal no passado ${ }^{13,6}$.

Finalmente, na última edição do consenso de asma grave da ATS/ERS em 2014, define-se asma grave como asma que requer tratamento com corticoide inalatório em dose alta associado a uma segunda medicação de controle (broncodilatador de longa ação ou antagonista de leucotrieno) e/ou corticoide sistêmico para manter controle adequado ou quando seu controle não é adquirido a despeito do tratamento de alta intensidade, após confirmação diagnóstica e identificação das comorbidades ${ }^{7}$.

A asma grave é considerada como não controlada, de acordo com critérios da ATS/ERS 2014, quando apresenta, após extensiva investigação, corrigidos fatores potencialmente modificáveis, técnica inalatória correta e adesão ao tratamento, qualquer um dos seguintes critérios: 1) Pobre controle dos sintomas: ACQ (Asthma Control Questionnarie) >1,5, ou ACT (Asthma 
Control Test) $<20$, ou não controle pelos critérios do GINA, após 3 meses de avaliação; 2) Exacerbações frequentes: 2 ou mais uso de corticoides sistêmicos (>3 dias cada) no último ano; 3) Exacerbações graves: pelo menos uma hospitalização em UTI ou VM no último ano; 4) Limitação ao fluxo aéreo: FEV1 $<80 \%$ do predito (na presença de FEV1/CVF reduzida) após uso de broncodilatador ${ }^{7}$.

O termo asma grave resistente ao tratamento (AGRT), amplamente utilizado na literatura atual incluindo estudos na faixa etária pediátrica, condiz com a definição de asma grave não controlada da ATS/ERS: pacientes asmáticos que mesmo após extensiva investigação, tratamento de comorbidades, técnica correta do uso das medicações e boa adesão ao tratamento, permanecem sem controle adequado ${ }^{9}$.

\subsection{Avaliação do fenótipo inflamatório}

\subsubsection{Definição de fenótipo e endotipo}

Fenótipo é definido como um conjunto de características observáveis de um organismo, resultantes da interação entre determinantes genéticos e influencia ambiental, que são relativamente estáveis mas não invariáveis com o tempo. Um fenótipo integra aspectos biológicos e clínicos variando de características moleculares, celulares, morfológicas e funcionais com o objetivo de melhorar a terapeutica do paciente. Por fim, esses fenótipos devem evoluir para endotipos de asma, que combinam características clinicas com vias de mecanismos de ação ${ }^{7}$. 
O termo endotipo, uma contração de endofenótipo, foi proposto em 2008 como um quadro conceitual para guiar novos achados sobre a heterogeneidade molecular da asma. Evidências claras sugerem que a asma é uma doença heterogênea e geneticamente complexa (>100 genes já foram descritos) que não pode ser explicada por apenas um mecanismo. ${ }^{14}$ Esse termo se distingue do fenótipo, que é qualquer característica ou traço observado de uma doença sem qualquer implicação com o mecanismo. A vantagem da classificação da asma em endotipos seria a de que cada um deles poderia ser alvo de tratamentos específicos para o mecanismo molecular causal ${ }^{15}$.

Um exemplo de endotipo, que tem sido descrito na asma é de que alguns pacientes têm alto Th2 (Th2-high) enquanto outros tem baixo Th2 (Th2-low) ${ }^{14}$.

\subsubsection{Métodos para avaliação dos fenótipos inflamatórios}

Existem diferentes métodos para medir os marcadores inflamatórios de pacientes com asma grave. Os métodos não invasivos: IgE, eosinófilos séricos, fração exalada de óxido nítrico (FeNO) e escarro induzido; e invasivos: lavado broncoalveolar (LBA) e biopsia endobronquica, que são indicados apenas para um grupo restrito de pacientes e em pesquisas.

As diferenças quantitativas das células inflamatórias medidas pelo escarro induzido e pelos métodos invasivos (LBA e biopsia) ocorrem porque avaliam compartimentos diferentes das vias áreas ${ }^{16}$.

Os mecanismos por trás do perfil inflamatório são complexos e variados e estão relacionados à sensibilidade aos corticosteroides ${ }^{7}$. Por exemplo, a asma 
eosinofílica foi associada patologicamente com espessamento da membrana basal e farmacologicamente com boa resposta ao tratamento com corticosteroides. Já a asma não-eosinofílica, um subgrupo considerável de asma que incluem pacientes com doença grave, parece ter relativa resistência ao tratamento com corticosteroides ${ }^{17}$.

\subsubsection{Fração exalada de óxido nítrico}

A medida da fração exalada de óxido nítrico (FeNO) é um método quantitativo, não invasivo, simples e seguro para avaliação da inflamação das vias áreas ${ }^{18}$.

O óxido nítrico (NO) está presente no ar exalado de todos os seres humanos e tem um papel na fisiopatologia de doenças pulmonares atuando como vasodilatador, broncodilatador, neurotransmissor e mediador inflamatório. Pacientes com asma podem apresentar altos níveis de FeNO e altos níveis de expressão da enzima óxido nítrico sintetase (NOS2) nas células do epitélio das vias áreas ${ }^{18}$. O NO liberado no ar exalado parece ter origem no epitélio respiratório como resultado de alta regulação da NOS2 secundária a inflamação. Portanto o NO exalado pode ser considerado como um marcador indireto da inflamação das vias aéreas ${ }^{18}$.

A atuação do NO nos pulmões é complexa. Como mediador próinflamatório, o NO pode atuar na hiperresponsividade brônquica. Entretanto, em condições fisiológicas, atua como mediador fraco de relaxamento da 
musculatura lisa e proteção da hiperresponsividade brônquica. O NO também pode participar nos mecanismos de defesa através de atividade antimicrobiana e citotóxica para as células tumorais ${ }^{18}$.

Vários estudos descrevem a relação entre FeNO e inflamação eosinofílica das vias aéreas medida através do escarro, lavado broncopulmonar e biopsias. Berry e colaboradores demonstraram que a medida da FeNO de 36 ppb tem uma sensibilidade e especificidade para eosinofilia no escarro maior que $3 \%$ de $78 \%$ e $72 \%$, respectivamente, em adultos asmáticos ${ }^{18,19}$. Por outro lado, em um estudo realizado por Shaw e colaboradores, a FeNO menor de 26 ppb foi associada com contagem diferencial de eosinófilos no escarro menor que $3 \%$. Portanto, a medida da FeNO elevada poderia predizer a presença de inflamação eosinofílica e, por inferência, uma resposta favorável ao tratamento com corticosteroides $^{18,20}$.

Uma revisão da Cochrane publicada em 2016 concluiu que o uso da FeNO para guiar tratamento em crianças asmáticas reduziu significativamente o número das que apresentaram uma ou mais exacerbações no período do estudo, mas não impactou nos sintomas clínicos diários ou doses de corticosteroides inalatórios. Concluiu-se que o uso da FeNO no manejo da asma em crianças pode ser benéfico em um subgrupo de pacientes no entanto não é recomendado para todas as crianças com asma ${ }^{21}$. 


\subsubsection{Escarro induzido}

A análise do escarro induzido é um método reprodutível, validado e não invasivo para o estudo da inflamação das vias aéreas. Este método consiste da produção de escarro induzido através da inalação de solução salina hipertônica e contagem de células no esfregaço, com técnica já padronizada, para avaliação do fenótipo inflamatório ${ }^{22}$. A indução do escarro utilizando solução salina a 3,5\% é segura em crianças com asma de difícil controle com FEV1 >65\% do predito. A taxa de sucesso descrita na literatura na obtenção do escarro induzido em crianças varia de $68 \%$ a $100 \%{ }^{23,24}$.

A inflamação das vias aéreas na asma pode ser categorizada em subtipos inflamatórios baseada na proporção de eosinófilos e neutrófilos no escarro induzido. Essa inflamação tem sido categorizada como eosinofílica, neutrofílica, mista e paucigranulocítica. O número de eosinófilos e neutrófilos no escarro apresenta uma grande variabilidade na asma grave com pacientes demonstrando nenhum ou altos níveis dessas células, a despeito do uso de altas doses de corticosteroides. Além disso, o perfil de células inflamatórias no escarro pode variar substancialmente ao longo dos meses ${ }^{25,} 26$.

A eosinofilia no escarro parece ser mais estável, especialmente na asma grave, quando examinada por longos períodos em adultos. Porém essa estabilidade parece ser menos presente nas crianças. Crianças com asma grave apresentam instabilidade significativa no fenótipo inflamatório alterando entre eosinofílico, neutrofílico, misto e paucigranulocítico sem qualquer preditor ${ }^{25}$. 
Portanto, em crianças com asma grave, o uso dos níveis de eosinófilos no escarro para guiar o tratamento, não apresentou benefícios ${ }^{8}$.

Além da avaliação das células inflamatórias é possível realizar dosagem de numerosos marcadores inflamatórios como citocinas, quimiocinas e fatores de crescimento, através de técnicas também padronizadas, no sobrenadante do escarro. O imunoensaio é o método de escolha para quantificação de mediadores devido sua conveniência, reprodutibilidade e especificidade ${ }^{27}$.

O dithiothreitol (DTT) é um agente mucolítico que se faz necessário no processamento do escarro para obtenção da dispersão das células, sem efeito adverso na contagem celular. Entretanto, ele pode reduzir as pontes dissulfeto presentes em vários mediadores inflamatórios como IL1, IL7, IL10, IL12, fator estimulador de colônias de granulócitos-macrófagos (GM-CSF), TGF- $\beta$, famílias dos interferons e TNF-a. Teoricamente, o DTT pode também interferir na captura de anticorpos pelos imunoensaios resultando em redução da sensibilidade ${ }^{27,29}$.

\subsubsection{Células inflamatórias}

\subsubsection{Eosinófilos}

O aumento do número de eosinófilos no sangue periférico e nas vias áreas é um traço característico na asma. Conceitualmente os indivíduos com asma atópica, que representa o maior subgrupo de pacientes asmáticos, acumulam eosinófilos nas vias aéreas através da ação de citocinas Th2 secretadas pelo subtipo Th2 das células T $^{17}$. 
Em crianças com asma grave a patologia das vias áreas é caracterizada pela eosinofila no lúmem (lavado broncoalveolar) e tecido (biopsia endobrônquica). Embora o padrão eosinofílico tenha melhor resposta ao tratamento com corticosteroides, muitas crianças com asma grave resistente ao tratamento apresentam uma eosinofilia persistente a despeito do tratamento antiinflamatório ${ }^{8}$. Existe pouca correlação entre eosinofilia e controle dos sintomas ou função pulmonar. Entretanto, terapias com alvo na inflamação eosinofílica utilizando anticorpos monoclonais para interleucina (IL)-5 tem demostrado redução significativa das exacerbações em adultos com asma grave. Este fato sugere um impacto especifico dos eosinófilos nas exacerbações contudo não foi confirmado o seu mecanismo de ação ${ }^{8,9}$.

Marcadores inflamatórios menos invasivos que o escarro induzido, como fração exalada de óxido nítrico (FeNO), lgE sérico e eosinófilos séricos, não foram representativos da eosinofilia no escarro em adultos com asma grave ${ }^{8}$. Portanto não existe um biomarcador único, periférico ou não invasivo, que possa representar a eosinofilia das vias aéreas. Dessa forma medidas conjuntas parecem ser mais úteis ${ }^{9}$.

\subsubsection{Neutrófilos}

A asma não-eosinofílica é um fenótipo da doença que pode estar presente nos pacientes com asma grave e é caracterizado por níveis normais de eosinófilos nas vias áreas e a presença de sintomas típicos de asma. Foi demonstrado que a subpopulação dominante das células inflamatórias no 
fenótipo não-eosinofílico são os neutrófilos e a citocina predominante é a IL-8, um potente quimiotático neutrofílico ${ }^{30}$.

O mecanismo para neutrofilia nas vias aéreas é menos conhecido e o papel dos neutrófilos na patogênese de asma brônquica permanece incerto. $\mathrm{Na}$ asma leve o número de neutrófilos nas vias áreas (escarro induzido, LBA e biópsias brônquicas) foi similar nos controles saudáveis. Entretanto, na asma grave, o número de células polimorfonucleares nos brônquios está elevado comparado com indivíduos normais. O número de neutrófilos apresenta-se aumentado no sangue periférico e nas vias áreas durante as exacerbações. A asma ocupacional também tem sido associada com aumento do número de neutrófilos no sangue periférico e no lavado broncoalveolar. Acredita-se que exposição ambiental, tais como poluição do ar, ozônio, vírus e bactérias, podem desencadear inflamação neutrofílica nas vias áreas ${ }^{30}$. Os corticoides podem eles mesmos contribuir para a neutrofilia em algum grau e fatores Th1 também podem ter uma função ${ }^{7}$.

Muitos estudos têm demonstrado que o aumento no número de neutrófilos nas vias áreas de asmáticos é uma potente fonte de citocinas pró-inflamatórias ${ }^{30}$. A imunidade Th17 tem sido implicada como causa de neutrofilia, primariamente em modelos animais, com alguns dados suportando essa evidencia na asma grave $^{7}$. No curso da asma, os neutrófilos liberam vários mediadores inflamatórios após sua infiltração nas vias aéreas durante os primeiros estágios de desenvolvimento da asma. Esse fenômeno é explicado pelo aumento das concentrações de IL-8 na circulação de pacientes asmáticos ${ }^{30}$. 
Diferentes estudos demonstraram que os neutrófilos dos asmáticos reagem de forma mais intensa ao estimulo de antígenos do que as células de indivíduos não-atópicos. Os neutrófilos desempenham um importante papel na imunidade inata. Suas funções podem ser divididas em imunomodulação e antimicrobiano. A fagocitose é uma das principais funções dos neutrófilos. E foi demostrado que indivíduos com asma não controlada apresentam fagocitose debilitada. A resistência a apoptose dos neutrófilos é uma característica da asma grave. Esse fenômeno pode estar ligado às altas doses de corticoides inalatórios que são promotores da sobrevivência dos neutrófilos ${ }^{30}$. Em resumo, o papel dos neutrófilos no desenvolvimento da asma é multidimensional. Sua presença e hiper-ativação foi associada com gravidade da asma ${ }^{30}$.

O papel dos neutrófilos em crianças com asma grave resistente ao tratamento permanece incerto. Todavia achados recentes sugerem um papel protetor neste grupo de pacientes 9 .

Os mecanismos envolvidos na asma grave de pacientes com pouca ou nenhuma inflamação permanecem não compreendidos mas podem envolver a ativação de elementos celulares residentes incluindo células de musculo liso, fibroblastos e neurônios ${ }^{7}$.

\subsection{Correlação do fenótipo inflamatório com parâmetros funcionais}


Obstrução grave de vias aéreas é uma característica em alguns fenótipos de asma grave, com estudos sugerindo que a inflamação eosinofílica e/ou neutrofílica possam contribuir para aumentar a limitação do fluxo aéreo. No estudo da Severe Asthma Research Program (SARP), uma coorte multicêntrica do National Institutes of Health/National Heart Lung Blood Institute conduzida para investigar os mecanismos da asma grave, foram caracterizados clusters pela obstrução grave das vias áreas, com reversibilidade ao broncodilatador, mas sem reversibilidade aos valores normais, e isso foi associado com o escarro neutrofílico ${ }^{7,31}$.

Crianças com asma grave frequentemente tem função pulmonar normal e sem resposta aguda ao broncodilatador. Crianças com FEV1 normal antes e após broncodilatador podem ter resposta pelo FEF 25-75, e este apresentou correlação positiva com FeNO. ${ }^{32}$ Entretanto, a utilização do FEF25-75 para a avaliação ou tratamento da asma grave é ainda incerto ${ }^{7}$.

Valores elevados de FeNO tem sido associados com fenótipo exacerbador na asma grave assim como ao rápido declínio no FEV1 em adultos $^{33,7}$.

\subsection{Paradigma da resposta imune}

O paradigma da resposta imune tipo 1 e tipo 2 descreve respostas imunes distintas que são reguladas principalmente por subpopulações de células CD4+ conhecidas com células T helper 1 (Th1) e T helper 2 (Th2) ${ }^{14}$. 
A resposta imune Th1 é caracterizada predominantemente pela atividade fagocítica. Dentre as citocinas envolvidas estão IL-2, INF gama e TNF alfa. Em contraste, na resposta imune Th2 as células secretam principalmente as citocinas IL-4, IL5 e IL13 que levam ao aumento da produção de IgE e inflamação eosinofílica. Além dos processos alérgicos a resposta imune tipo 2 é induzida também por parasitas helmintos ${ }^{34}$. A resposta imune tipo 2 nas vias aéreas são principalmente mediadas por eosinófilos, mastócitos, basófilos, células Th2, células linfoides inatas tipos 2 e células produtoras de $\lg \mathrm{E}^{7,14} 34$.

O papel da imunidade inata, assim como o da imunidade adaptativa, tem sido reconhecido na patogênese da asma. Após exposição a estímulos ambientais (alérgenos, infecção e poluição) a ativação do epitélio libera citocinas como IL25, IL33 ou TSLP que contribuem para o início dos mecanismos da imunidade inata ${ }^{9}$. As células dendríticas, mastócitos, células linfoides inatas tipo 2 e basófilos, são induzidas pela liberação das citocinas epiteliais inatas. Especialmente na asma grave pediátrica, ocorre aumento da expressão da citocina IL-33 no tecido brônquico e uma associação com remodelamento e resistência aos corticosteroides ${ }^{9,35}$.

A ativação das células $T$ podem ser suprimidas pelas células $T$ regulatórias (Treg.) CD4+CD25+ ${ }^{36}$. Além disso, as células Treg. podem controlar as respostas imunes alérgeno-específicas e sua redução em número ou função podem contribuir para doenças alérgicas e asma ${ }^{9}$. No entanto, poucos estudos têm investigado o papel das células Treg. na asma grave pediátrica. Em adultos com asma grave comparados a indivíduos saudáveis, foram reportados baixos níveis dessas células no sangue e escarro assim como redução de sua função 
durante as exacerbações ${ }^{37}$. Entretanto, um estudo que comparou o número de células Treg no lavado broncoalveolar entre pacientes adultos com asma moderada a grave com asmáticos leves, reportou um aumento dessas células no grupo de asma grave ${ }^{38}$. Em crianças asmáticas, as células Treg estão reduzidas no lavado broncoalveolar e no sangue ${ }^{39}$. As células Treg podem atuar através das citocinas IL-10 e TGF- $\beta$. A IL-10 é uma potente citocina antiinflamatória que inibe a produção de citocinas inflamatórias assim como a função dos eosinófilos, além de inibir a lgE9 .

Apenas metade de um grupo de pacientes com asma leve a moderada apresentaram o fenótipo Th2-high, que é caracterizado por um grau elevado de hiper-responsividade brônquica, alta concentração sérica de lgE e aumento de eosinófilos séricos e nas vias aéreas ${ }^{34}$. Esse achado leva a dicotomização da asma em dois endotipos: Th2-high e Th2-low ${ }^{34}$. Entretanto, as evidencias do padrão TH2 em crianças asmáticas graves permanece controverso ${ }^{7}$.

Embora o perfil inflamatório de alto Th2 seja predominantemente eosinofílico e baixo Th2 seja caracterizado pela ausência de padrão eosinofílico permanece incerto se as alterações estruturais associadas também serão distintas nessas duas categorias ${ }^{40}$.

\subsection{Papel das citocinas}


As citocinas atuam na promoção da inflamação crônica e remodelamento das vias aéreas através de diferentes ações nas células inflamatórias e estruturais ${ }^{34}$.

As respostas imunes na asma podem ser mediadas por linfócitos Th1, Th2 e Th17. A inflamação Th2 está associada com recrutamento de leucócitos e ativação nas vias aéreas (principalmente linfócitos, eosinófilos e mastócitos) e produção de citocinas incluindo IL-4, IL-5 e IL-13 $3^{41,42}$.

A IL-4 é produzida predominantemente por células Th2, mas também pode ser secretada por basófilos e eosinófilos. Ela está envolvida no aumento de IgE, hipersecreção brônquica e hiper-reatividade brônquica ${ }^{43}$.

A interleucina 13 compartilha $30 \%$ de homologia com IL-4 e é secretada pelas células Th2, células linfóides inatas do tipo 2 (ILC2s), mastócitos, basófilos e eosinófilos. $\mathrm{Na}$ asma, os efeito da IL-13 incluem diferenciação das células caliciformes, ativação dos fibroblastos, aumento da hiperresponsividade brônquica, e produção de lgE pelas células $B{ }^{44}$.

A interleucina 5 (IL-5), produzida pelas células Th2 e ILC2s, tem papel importante na maturação e diferenciação dos eosinófilos ${ }^{34}$. Juntamente com a eotaxina, a IL-5 mobiliza os eosinófilos e seus percursores para a circulação, além de aumentar a sobrevida e a citotoxicidade dos eosinófilos. O infiltrado eosinofílico e sua degranulação levam a liberação de produtos citotóxicos que contribuem para o dano do epitélio das vias aéreas, hipersecreção de muco pelas células caliciformes, hiperresponsividade brônquica e alteração do batimento ciliar $^{34}$. 
No curso da asma, os neutrófilos também produzem uma grande variedade de citocinas e mediadores inflamatórios. As principais citocinas inflamatórias liberadas pelos neutrófilos são: IL-1, IL-3, IL-6, IL-8, IL-9, IL-12, TNFa, TGF- $\beta$, IFN-ץ (interferon gama), GM-CSF (fator estimulador de colônia de granulócitos-macrófagos), e MIP (proteína inflamatória macrofágica) ${ }^{30}$. Neutrófilos também são fontes de leucotrieno B4 (LTB4) e fator de ativação plaquetária $(\mathrm{PAF})^{30}$.

A IL-9 regula as células Th2, eosinófilos, mastócitos e funções das células epiteliais das vias aéreas. A IL-8 é sabidamente um potente quimioatático neutrofílico e recentemente tem sido demonstrada com um ativador de neutrófilos ${ }^{30}$.

O Fator de necrose tumoral $\alpha$ (TNF $\alpha)$ é uma citocina pró-inflamatória Th1 que induz a inflamação das vias aéreas, hiperresponsividade brônquica, hipersecreção de muco e ativação de macrófagos ${ }^{34}$. Além disso, o TNF- $\alpha$ estimula a migração trans-membrana basal de eosinófilos e foi associado com fenótipo de asma grave e refratária ${ }^{41}$. O TGF- $\beta$ estimula a proliferação de fibroblastos nas vias áreas ${ }^{42}$.

A IL-1 é um mediador central da imunidade inata e inflamação. A família IL-1 inclui 7 ligantes com atividades agonistas (IL1-a e B, IL-18, IL33, IL-36 a e B e gama) e três receptores antagonistas (IL-1 Ram IL-36 Ra, IL-38), e uma citocina antiinflamatoria (IL37) ${ }^{7}$. A expressão elevada de IL-33 e sua correlação com TNF- $\alpha$ refletiu o processo inflamatório observado em pulmões de pacientes asmáticos jovens. Charred et al encontraram uma alta expressão de TNF- $\alpha$, IL- 
$1 \beta$, IL-6 e IL17 no escarro induzido de crianças asmáticas, contrastando com baixos níveis de IL-3742 e recentes abordagens genômicas tem sugerido aumento na IL-1 $\beta$ em alguns asmáticos, em conjunto com neutrofilia?

A MCP-1 (Proteina quimiotática de monócitos-1) é uma quimiocina C-C que é produzida espontaneamente pelas células do epitélio brônquico ${ }^{45}$. É responsável pelo recrutamento de células inflamatórias e está envolvida na patogênese da asma alérgica. A MCP-1 media a ativação e recrutamento de monócitos, mastócitos, basófilos, eosinófilos e linfócitos T helper tipo 2 (Th2) do compartimento celular para o espaço brônquico ${ }^{43}$. Estudos sugerem que ela esteja envolvida na hiperreatividade brônquica. Além disso, produção de MCP-1 pode ser aumentada significativamente em resposta a diversos estímulos inflamatórios, tipicamente pelo IFN-y, TNF- $\alpha$, IL-1 $\beta$ e LSP bacteriano e pelas citocinas IL-4 e IL-13 33 .

A IL-10 é produzida por linfócitos Th1, células T citotóxicas, mastócitos, monócitos, linfócitos B e eosinófilos ${ }^{45}$. Os fatores envolvidos na indução da produção da IL-10 ainda são incertos. Os corticosteroides e a ciclosporina A aumentam sua produção em vitro ${ }^{46}$. A IL-10 inibe a resposta inflamatória, e defeitos na produção ou ação da $\mathrm{IL}-10$ estão correlacionados ao desenvolvimento de distúrbios inflamatórios, incluindo doença inflamatória intestinal. Baixos níveis de IL-10 foram observados em pacientes com asma ${ }^{47}$. No pulmão, a IL10 inativa os neutrófilos, eosinófilos e mastócitos. Portanto a IL10 está criticamente envolvida com inflamação pulmonar e asma. Kawano et al. demostraram que a produção da IL-10 por macrófagos intersticiais previne a inflamação pulmonar através da regulação do infiltrado neutrofílico e da 
produção de células caliciformes produtoras de muco, através da inibição da IL$13^{48}$. A IL-10 induz a expressão da IL-5 no pulmão durante a inflamação alérgica e regula negativamente os genes relacionados a Th1 e Th17, como IL-12, IL-1 $\beta$, IL-6, TNF- $\alpha$ e GM-CSF ${ }^{48}$.

O fator estimulador de colônia de granulócitos e macrófagos (GM-CSF) é um regulador importante das células inflamatórias da linhagem mieloide e tem sido implicado na asma e DPOC ${ }^{49}$. Ele é produzido tanto por células Th1 e Th2 e por uma variedade de células estruturais e inflamatórias, incluindo células do epitélio respiratório, músculo liso, fibroblastos, mastócitos, eosinófilos e macrófagos ${ }^{45}$. O GM-CSF, produzido abundantemente pelas células epiteliais pulmonares, promove a diferenciação e proliferação das células hematopoiéticas progenitoras de granulócitos/macrófagos e regula a sobrevida e função de neutrófilos, eosinófilos, macrófagos e células dendríticas ${ }^{50}$. Na asma e DPOC a expressão de GM-CSF é elevada no escarro e no lavado broncoalveolar ${ }^{50}$. 0 GM-CSF regula a imunidade e inflamação da mucosa e função neutrofílica. Foi demonstrado que a hiperexpressão do GM-CSF promove a sensibilização a alérgenos, resultando no aumento da inflamação das vias áreas. Foi também relatado um papel central na hiperresponsividade causada por partículas de escape de diesel, um importante poluente aéreo ${ }^{51}$. Sua importância nas doenças de vias áreas é suportada por evidências em modelos animais de asma e DPOC em que a administração de anticorpos anti GM-CSF atenuou a resposta inflamatória eosinofílica e neutrofílica, respectivamente ${ }^{49}$. Seu nível no pulmão se correlacionou com lesão tecidual e gravidade da doença ${ }^{52}$. 
As células Th17 são células T CD4 que expressam IL-17A, IL-17E e IL22, e são capazes de mediar a ativação neutrofílica pela via de produção da IL$8^{53}$. Estímulos alergênicos e poluição podem desencadear a inflamação das vias aéreas mediada pela Th17 na asma. Além disso, a hiperexpressão das interleucinas IL-17A e IL-17F têm sido encontradas no tecido pulmonar de pacientes com asma, com níveis de expressão correlacionados com gravidade da asma, especialmente em pacientes com asma neutrofílica resistente a corticoide $^{34}$.

A tabela 1 apresenta um resumo das principais citocinas envolvidas na fisiopatologia da asma e seus mecanismos de ação. 
Quadro 1: Principais citocinas e suas características:

\begin{tabular}{|c|c|c|}
\hline Citocinas & Células produtoras & Ações \\
\hline $\mathrm{IL}-4$ & $\begin{array}{l}\text { Th2, macrófagos, basófilos, } \\
\text { mastócitos, eosinófilos }\end{array}$ & $\begin{array}{l}\text { Aumento lgE } \\
\text { Hipersecreção brônquica } \\
\text { Hiper-reatividade }\end{array}$ \\
\hline IL-13 & $\begin{array}{l}\text { Th2, ILC2, mastócitos, basófilos, } \\
\text { eosinófilos. }\end{array}$ & $\begin{array}{l}\text { Diferenciação cel. Caliciformes } \\
\text { Ativação fibroblastos } \\
\text { Aumento lgE } \\
\text { Hiper-reatividade }\end{array}$ \\
\hline IL-5 & Th2, ILC2 & $\begin{array}{l}\text { Maturação e diferenciação de } \\
\text { eosinófilos }\end{array}$ \\
\hline IL-9 & Neutrófilos & $\begin{array}{l}\text { Regula célula Th2, eosinófilos, } \\
\text { mastócitos e funções das células } \\
\text { epiteliais. }\end{array}$ \\
\hline IL-8 & Neutrófilos & Quimioatático e ativador de neutrófilos \\
\hline TNF- $\alpha$ & Neutrófilos, células Th1 & $\begin{array}{l}\text { Hiper-reatividade } \\
\text { hipersecreção de muco, migração de } \\
\text { eosinófilos }\end{array}$ \\
\hline INF-y & Neutrófilos, células Th1 & Inflamação neutrofílica \\
\hline IL-1 & Neutrófilos & Mediador central da imunidade inata \\
\hline MCP-1 & Células do epitélio brônquico & $\begin{array}{l}\text { Recrutamento de células inflamatórias } \\
\text { Hiper-reatividade }\end{array}$ \\
\hline $\mathrm{IL}-10$ & $\begin{array}{l}\text { Th1, Th2, cel. T citotóxicas, } \\
\text { mastócitos, monócitos, linf. B, } \\
\text { eosinófilos }\end{array}$ & $\begin{array}{l}\text { Inibe resposta inflamatória. } \\
\text { Induz expressão IL-5. }\end{array}$ \\
\hline GM-CSF & $\begin{array}{l}\text { Th1, Th2, epitélio respiratório, } \\
\text { eosinófilos, neutrófilos e outras }\end{array}$ & $\begin{array}{l}\text { Sobrevida neutrófilos e eosinófilos, } \\
\text { Hiper-reatividade } \\
\text { Sensibilização }\end{array}$ \\
\hline IL-17 & Th17 & Ativação neutrofílica \\
\hline
\end{tabular}


3 JUSTIFICATIVA 


\section{Justificativa}

O Instituto da Criança do Hospital das Clinicas da Faculdade de Medicina da USP, por ser um hospital de nível terciário, atende pacientes referenciados com asma de intensidade moderada e grave. Apesar do tratamento adequado, muitos pacientes permanecem sintomáticos ou com alterações significativas de função pulmonar e, portanto, são considerados não controlados.

O não controle da asma grave pode estar associado com: má adesão ao tratamento, presença de comorbidades, resistência à corticoterapia e fenótipo inflamatório ${ }^{54}$.

Os estudos sobre asma grave resistente ao tratamento em crianças são escassos e a associação entre os padrões inflamatórios, aspectos clínicos e fisiopatológicos ainda não foram totalmente elucidados nesse grupo de pacientes. A caracterização clínica, funcional e inflamatória dos pacientes com asma grave na população brasileira tem importância uma vez que se conhece a interferência de fatores genéticos e ambientais na expressão da doença. Avanços têm sido feitos no tratamento da asma grave em adultos com alvo nos fenótipos inflamatórios e seus marcadores, porém os resultados não podem ser extrapolados para os pacientes pediátricos. 
4 OBJETIVOS 


\section{Objetivos}

O objetivo primário deste estudo é identificar e comparar os fenótipos e endotipos inflamatórios dos pacientes pediátricos com asma grave controlada e asma grave resistente ao tratamento, através da análise do escarro induzido e fração exalada de óxido nítrico.

Os objetivos secundários são:

- comparar os parâmetros funcionais entre os dois grupos de pacientes e correlacionar com os marcadores inflamatórios;

- identificar as citocinas envolvidas no processo inflamatório desses pacientes através do escarro induzido; e

- correlacionar controle da asma, medido pelo escore de ACT, com os marcadores inflamatórios. 
5 MÉTODOS 


\section{Métodos}

Este estudo faz parte do projeto de pesquisa intitulado: "Fatores clínicos e laboratoriais associados com a asma grave de difícil controle em crianças e adolescentes", aprovado pela Comissão de Ética para Análise dos Projetos de Pesquisas do Hospital das Clínicas da FMUSP número de protocolo: 0650/10 (Anexo A); e contemplado com auxílio regular FAPESP processo número: 2012/20532-4.

Trata-se de um estudo de Coorte Prospectivo conduzido no período de Maio de 2013 a Setembro de 2015 em um ambulatório terciário de pneumologia do Instituto da Criança da Faculdade de Medicina do Hospital das Clínicas da Faculdade de Medicina da USP, na cidade de São Paulo.

Antes do início do estudo todos os pacientes foram informados sobre os propósitos do estudo em questão, assim como dos possíveis riscos envolvidos, através do termo de consentimento informado livre e esclarecido (Anexo B).

\subsection{Critérios de inclusão e exclusão:}

Os critérios de inclusão foram: crianças e adolescentes na faixa etária entre 6 a 18 anos e portadores de asma grave, definidas pela necessidade do uso de corticosteroides inalatórios em dose média a alta ( 800 mcg de budesonida ou 500 mcg de fluticasona) associados com broncodilatador de longa duração, 
associado ou não ao antagonista de leucotrieno, para o bom controle da doença, ou que mesmo assim não conseguem obter o controle da doença ${ }^{1}$.

Os critérios de exclusão foram: crianças com diagnóstico confirmado de outras patologias pulmonares crônicas antes do início do estudo (fibrose cística, discinesia ciliar, bronquiolite obliterante, displasia broncopulmonar), patologias não pulmonares significativas e inabilidade de realizar prova de função pulmonar adequadamente.

\subsection{Desenho do estudo}

Os pacientes foram avaliados através de anamnese e exame físico e acompanhados por três visitas consecutivas com intervalo de um mês da primeira para segunda e dois meses da segunda para terceira (Figura 1).

Na primeira avaliação foi realizado: anamnese detalhada e exame físico; averiguada a técnica do uso dos dispositivos inalatórios e adesão ao tratamento; realizada espirometria, pletismografia, medida da fração expirada de óxido nítrico (FeNO), coleta de escarro induzido e solicitados exames laboratoriais (hemograma, IgE, alfa 1-antitripsina, protoparasitológico de fezes em 3 amostras). Solicitado também testes cutâneos de hipersensibilidade imediata (prick test) para os principais aeroalérgenos e Aspergillus (considerado atopia a presença de pelo menos um aeroalérgeno positivo), nasofibrolaringoscopia e pHimpedanciometria de 24 horas (Anexo C). Foi aplicado o questionário de controle Asthma control test (ACT) ${ }^{55}$ (Anexo D) validado para língua portuguesa, 
devido a sua consistência e utilização em estudos publicados com a mesma faixa etária ${ }^{56}$.

Na segunda visita, após um mês, foram reavaliados os sintomas, técnica inalatória e adesão ao tratamento. A adesão ao tratamento foi averiguada pela anamnese e pelos registros de retirada de medicamentos na farmácia, sendo considerado boa adesão ao tratamento os pacientes que utilizassem, no mínimo, $85 \%$ das doses prescritas da medicação ${ }^{57}$. Verificados exames e tratadas comorbidades como sinusopatia, refluxo gastroesofágico e parasitose intestinal. O diagnóstico de sinusopatia foi realizado clinicamente e com ajuda dos exames (tomografia dos seios da face e nasofibrolaringoscopia) e foi tratado com amoxicilina associado a clavulanato de potássio por 10 dias. $O$ tratamento da DRGE também foi baseado nos dados clínicos e prescrito omeprazol para aqueles que ainda não faziam uso. A parasitose intestinal, diagnosticada pelo exame protoparasitológico de fezes, foi tratada com albendazol.

$\mathrm{Na}$ terceira visita, após três meses, os pacientes foram classificados como: asma grave controlada e asma grave resistente ao tratamento, de acordo com os critérios da ATS/ERS ${ }^{7}$ e realizado novamente medidas da FeNO, espirometria e pletismografia, coleta de escarro induzido e aplicação dos questionários.

Os pacientes foram orientados a fazer uso de salbutamol spray dosimetrado com espaçador valvulado nas crises e exacerbações da asma. Caso fosse necessário ir a algum serviço de emergência, o uso e corticosteroides sistêmicos ou antibióticos para exacerbações estaria a cargo do médico do próprio serviço. Após uma exacerbação e/ou uso de corticosteroides sistêmicos 
foi obedecido um intervalo de no mínimo 15 dias para realizar a visita do estudo e coleta de escarro induzido.

Critérios de Asma Grave Não Controlada - ATS/ERS: Alteração de um dos seguintes itens:

1) Mau controle dos sintomas: ACT <20 (ou "não bem controlado" pelos guidelines NAEPP ou GINA guidelines por mais de 3 meses de seguimento);

2) Exacerbações graves frequentes: 2 ou mais com uso de corticóide sistêmico (>3 dias em cada episódio) no ano anterior;

3) Exacerbações graves: pelo menos 1 hospitalização, necessidade de UTI ou VM no ano anterior;

4) Limitação fluxo VA: VEF1<80\% predito pós-BD (na presença de FEV1/CVF reduzido) ${ }^{7}$. 


\section{Recrutamento}

Pacientes de 6 a 18 anos, em seguimento a pelo menos 6 meses, com diagnóstico de asma grave de acordo com critérios do Global Initiative for Asthma (GINA).

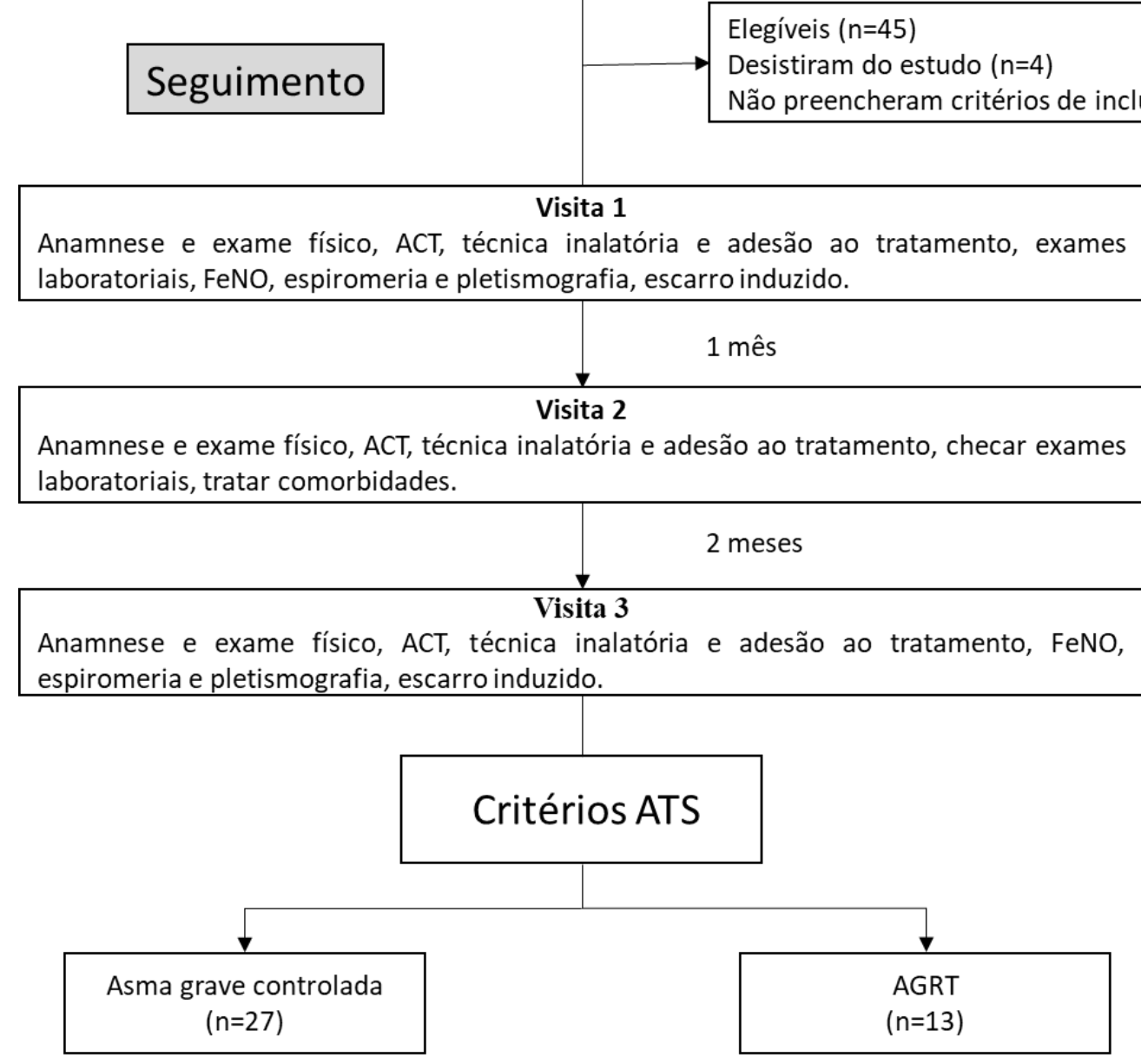

Figura 1: Desenho do estudo

\subsection{Prova de função pulmonar:}

Foi realizada espirometria e pletismografia com o equipamento Sensormedics Vmax 50 na primeira e na terceira visitas (pré e pós- 
broncodilatador com $400 \mathrm{mcg}$ de salbutamol spray oral) no laboratório de prova de função pulmonar do Instituto da Criança do Hospital das Clínicas-FMUSP, pelas técnicas de função pulmonar habilitadas para tal exame. Esses exames foram realizados de acordo com as técnicas padronizadas pela American Thoracic Society -ATS 58 .

Foram utilizados os valores de referência do Global Lung Initiative ${ }^{59,60}$ para valores espiromêtricos e valores de referência de Moris-Polgar e critérios de normalidade de Stocks e Quanjer para valores da pletismografia ${ }^{61}$. Foram avaliados os seguintes parâmetros: VEF1: volume expiratório forçado no primeiro segundo, CVF: capacidade vital forçada, VEF1/CV: relação entre volume expiratório forçado no primeiro segundo e capacidade vital lenta, FEF 25-75\%:fluxo expiratório forçado entre $25-75 \%$ da manobra da CVF, CPT: capacidade pulmonar total, VR: volume residual, VR/CPT: relação entre volume residual e capacidade pulmonar total, Raw: resistência, Gaw: condutância.

Foi utilizado como critério de resposta ao broncodilatador o critério de Bussamra 2005: incremento do VEF1 em 14\% e 265mL em relação ao basal, 62 por ter sido obtido de crianças asmáticas e, portanto, mais apropriado para nossa amostra.

\subsection{Medida da fração expirada de óxido nítrico:}

As medidas online da fração expirada de óxido nítrico (FeNO) foram realizadas na primeira e na terceira visitas por quimiluminescência através de 
um único sopro com fluxo expiratório de $50 \mathrm{ml} / \mathrm{s}$ com o aparelho NIOX MINO®, antes da pletismografia e da coleta do escarro ${ }^{18}$, pelas pesquisadoras do estudo.

Os níveis de FeNO foram classificados como: altos se FeNO >50ppb em crianças $\geq 12$ anos, e $>35$ ppb se $<12$ anos; intermediário se FeNO = 25-50ppb em $\geq 12$ anos, e 20 a 35 ppb em $<12$ anos, e FeNO baixo $<25 p p b$ em $\geq 12$ anos e $<20 \mathrm{ppb}$ em $<12$ anos, de acordo com as diretrizes da American Thoracic Society -ATS $2011^{18}$.

\subsection{Escarro induzido:}

A indução do escarro foi realizada após pletismografia pósbroncodilatador (400 mcg de Salbutamol spray administrados com espaçador valvulado), na ausência de exacerbação e intervalo mínimo de duas semanas após uso de corticosteroide oral. Nos pacientes com VEF1 maior ou igual a $65 \%$ do previsto foram realizadas quatro nebulizações por 5 minutos, com solução salina hipertônica 3\%. Esta concentração foi utilizada devido demonstração de sua segurança em estudo com crianças com asma grave ${ }^{24}$. Os pacientes com VEF1 < $65 \%$ do previsto receberam nebulizações somente com solução salina fisiológica (SSF). As nebulizações foram realizadas com compressor Proneb e nebulizador Pari com peça bocal portando válvula expiratória. Após cada nebulização, foi solicitado ao paciente para assuar o nariz e enxaguar a boca com água para evitar a contaminação com saliva e, na sequência, tossir e escarrar no frasco. O tempo máximo de nebulização previsto foi de 20 minutos e a quantidade mínima de escarro aceitável foi 0,5 ml. A presença de dispneia, 
sibilância e/ou queda do VEF1 $>20 \%$ em relação ao inicial foi considerado motivo para suspensão do procedimento de indução e administração de 200 mcg de salbutamol inalatório (Anexo E).

A coleta e o processamento foram realizados pelas pesquisadoras, transportado o material em isopor e gelo e tempo inferior a 2 horas entre a coleta e o início do processamento. O processamento do escaro foi realizado no laboratório LIM 20 da Faculdade de Medicina da USP através da técnica descrita por Pizzichini22 e está resumido na figura 2. O material coletado foi colocado numa placa de Petri, separado o escarro da saliva com uma pipeta de polipropileno e pesado o escarro em balança de alta precisão. Ao invés do uso de DTT, foi adicionado o mesmo volume de escarro de PBS, ou até $2 x$ seu volume se material muito espesso (para não interferir na análise posterior das citocinas no sobrenadante) e, após centrifugação, o sobrenadante foi armazenado para posterior análise das citocinas em freezer $-70^{\circ} \mathrm{C}$. Ao botão celular foi acrescentado DTT a $0,1 \%$, colocado em banho-maria a $37^{\circ} \mathrm{C}$, filtrado e, após nova centrifugação, foi obtido botão celular. A viabilidade e a contagem celular total foram verificadas na câmara de Neubauer e sob microscopia óptica, considerando-se, no máximo, $50 \%$ de células não-viáveis e $80 \%$ de células escamosas. As lâminas foram coradas com Leishman e lidas uma ou duas lâminas até a contagem de 400 células não-escamosas e não-metacromáticas por uma bióloga e pesquisadora com grande experiência neste campo, referindose os dados diferenciais em termos de porcentagem ${ }^{24,63}$ (Anexo F).

O padrão inflamatório do escarro foi classificado em três diferentes padrões: 1) "eosinofílico" (eosinófilos $>2.5 \%$, neutrófilos $\leq 54 \%$ ); 2) "misto" 
(eosinófilos $>2.5 \%$, neutrófilos $>54 \%$ ); e 3 ) "neutrofílico" (eosinófilos $\leq 2.5 \%$, neutrófilos $>54 \%$ ) que tem sido empregada na população pediátrica, incluindo estudos em asma grave ${ }^{23,24}$. 


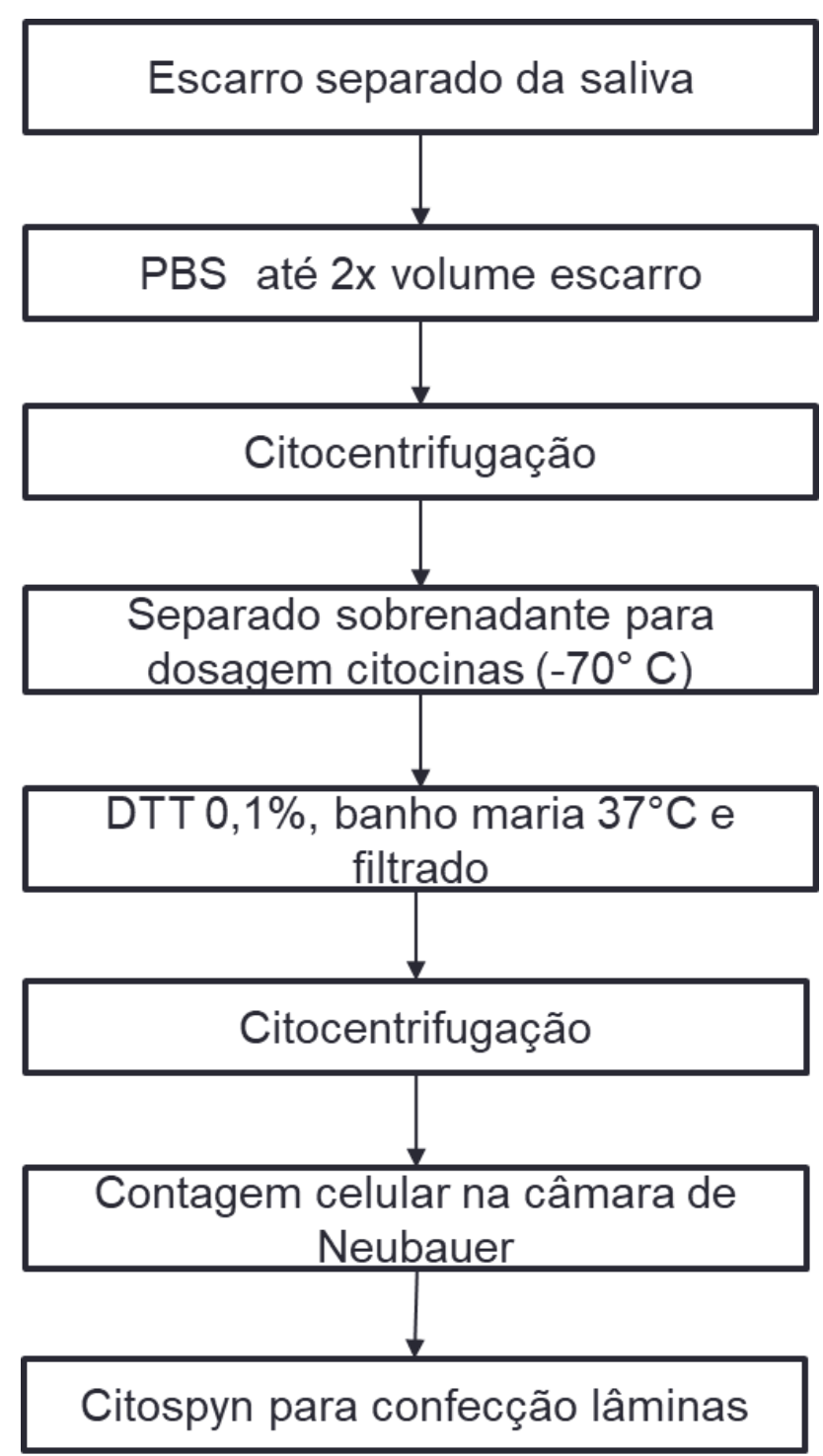

Figura 2: Processamento do escarro induzido

\subsection{Avaliação citocinas:}

O Immunoassayé o método de escolha para quantificação de mediadores no sobrenadante do escarro devido sua conveniência, reprodutibilidade e especificidade ${ }^{27}$. As citocinas foram quantificadas no sobrenadante de todas as amostras de escarro com quantidade suficiente para análise $(0,5 \mathrm{~mL})$ utilizando 
o sistema de análise "Bio-plex Pro Humana Cytokine 17-Plex immunoassay", para detecção das citocinas: IL-1, IL-2, IL-4, IL-5, IL-6, IL-7, IL-8, IL-10, IL12, IL13, IL17, G-CSF, GM-CSF, IFN-y, MCP-1, MIP-1 $\beta$, TNF- $\alpha$ (Bio-Rad Laboratories) $^{64}$.

As amostras foram analisadas no equipamento Bio-plex 200 (Bio-rad) no laboratório LIM 24 da Faculdade de Medicina da USP.

O teste de citocina com o Bio-Plex é realizado para quantificar múltiplas citocinas ao mesmo tempo na amostra a ser avaliada. O luminex possui o princípio similar ao ELISA sanduíche. Micro-esferas coloridas fluorescentes (também chamadas de beads) ligam-se de forma covalente aos anticorpos de captura. Os anticorpos de captura são colocados diretamente contra 0 biomarcador desejado. Após uma série de lavagens para remover as proteínas não ligadas, anticorpos de detecção são adicionados para criar o complexo sanduíche. A detecção final do complexo é formada com a adição do conjugado de estreptavidina-ficoeritrina. As micro-esferas possuem cores distintas que determinam os biomarcadores diferentes e a ficoeritrina serve como um indicador fluorescente para determinação da concentração. Para uma perfeita sensibilidade, é importante preparar adequadamente amostras e diluições da curva padrão (Anexo G).

Resumidamente, micro-esferas revestidas com anticorpos monoclonais contra os 17 alvos diferentes analisados foram adicionadas aos poços. Amostras e padrões (variando de 0,1 a $10.000 \mathrm{pg} / \mathrm{mL}$ para cada análise) foram pipetados nos poços e incubados. Os poços foram lavados e aspirados com lavadora magnética na qual as micro-esferas ficaram retidas na placa pela ação de um imã (Bio-plex PRO II Wash Station). Após lavagem, uma mistura de anticorpos 
biotinilados secundários foi adicionado e incubado novamente. A estreptavidina conjugada com a proteína fluorescente, R-ficoeritrina (estreptavidina-RPE) foi adicionada e incubada por um breve período. Após a lavagem para remoção dos reagentes não aderidos foi adicionada aos poços (mínimo de 100 por análise) uma solução tampão (Luminex®, MiraiBio, Alameda, CA) para serem analisadas no analisador de microesferas (Bio-plex 200). As concentrações das amostras desconhecidas (antígenos nas amostras de plasma) foram estimadas a partir da curva padrão (anexo G), utilizando o Bio-Plex Manager Software (Bio-Rad Laboratories, Hercules, CA). Os níveis das citocinas foram expressos em pg/mL.

Os níveis mínimos de detecção das diferentes citocinas são: IL-1: 13,7 $\mathrm{pg} / \mathrm{mL}, \mathrm{IL}-2: 1,24 \mathrm{pg} / \mathrm{mL}, \mathrm{IL}-4: 0,45 \mathrm{pg} / \mathrm{mL}, \mathrm{IL}-5: 2,18 \mathrm{pg} / \mathrm{mL}, \mathrm{IL}-6: 1,38 \mathrm{pg} / \mathrm{mL}$, IL7:1 $\mathrm{pg} / \mathrm{mL}, \quad \mathrm{IL}-8: 1,23 \mathrm{pg} / \mathrm{mL}, \quad \mathrm{IL}-10: 0,71 \mathrm{pg} / \mathrm{mL}, \quad \mathrm{IL} 12: 5,75 \mathrm{pg} / \mathrm{mL}, \quad \mathrm{IL}-13: 1,14$ pg/mL, IL17:2,9 pg/mL, G-CSF:6,76 pg/mL, GM-CSF:4,12 pg/mL, IFN- $/ 1,31$ $\mathrm{pg} / \mathrm{mL}$, MCP-1:2,35 pg/mL, MIP-1ß:2,9 pg/mL, TNF- $\alpha: 3,11 \mathrm{pg} / \mathrm{mL}$.

\subsection{Análise Estatística}

A amostra foi de conveniência, mas permitiu encontrar uma diferença entre as médias equivalente a um desvio padrão para um poder de teste de $80 \%$ com valor de $\mathrm{p}$ de $5 \%$. 
Foram utilizados os softwares GraphPad Instat, GraphPad Prism e Med Calc para as análises estatísticas. Para análise descritiva foram empregados cálculos de médias e desvios padrões, determinação da mediana e percentis, dependendo da variável estudada. Para variáveis de distribuição normal foi utilizado o teste T Student. Para variáveis sem distribuição normal foram empregados o Teste Mann-Whitney, para medidas isoladas, e Wilcoxon, para medidas pareadas. O Teste exato de Fisher foi empregado para comparação de proporções nas variáveis qualitativas. Foi utilizada a correlação de Spearman, para as variáveis não paramétricas. Foi considerado significativo um valor de $p$ $<0,005$. 
6 RESULTADOS 


\section{Resultados}

Foram recrutados 45 pacientes com diagnóstico de asma grave pelo critério vigente do GINA em tratamento adequado por pelo menos seis meses, com idade entre 6 a 18 anos, atendidos no ambulatório de Pneumologia do Instituto da Criança da Faculdade de Medicina da USP no período de maio de 2013 a maio de 2015. Foram excluídos diagnósticos de fibrose cística, deficiência de alfa 1-antitripsina e discinesia ciliar. Quatro pacientes desistiram do protocolo e um paciente foi excluído devido à incapacidade de realização adequada da prova de função pulmonar, totalizando 40 pacientes.

\subsection{Dados demográficos e clínicos:}

Do total de pacientes incluídos $62,5 \%$ eram do sexo masculino com uma idade média de 12,8 anos de vida, apenas cinco pacientes eram de etnia afrodescendente. A mediana da idade do início dos sintomas foi de 12 meses e do início do tratamento foi de cinco anos. Noventa e cinco por cento dos pacientes apresentaram histórico familiar de atopia e $22,5 \%$ contato domiciliar com tabagismo. Quinze pacientes $(37,5 \%)$ relataram algum alérgeno no ambiente domiciliar e 95\% apresentavam diagnóstico de rinite alérgica.

Todos os pacientes estavam em tratamento pelo menos seis meses antes do recrutamento. A maioria dos pacientes $(77,5 \%)$ estava em uso da associação budesonida $400 \mathrm{mcg}$ e formoterol $12 \mathrm{mcg}$ duas vezes ao dia e o restante em uso 
da associação fluticasona $250 \mathrm{mcg}$ e salmeterol $50 \mathrm{mcg}$ duas vezes ao dia. Vinte e dois pacientes (55\%) estavam em uso também de antagonista de leucotrieno, apenas um em uso de corticoide sistêmico oral em baixa dose, que foi possível suspender no primeiro mês de seguimento.

Em relação ao uso dos dispositivos inalatórios, $82,5 \%$ demonstraram técnica correta e $62,5 \%$ reportaram boa adesão ao tratamento na primeira avaliação. Na visita 3 todos os pacientes apresentaram técnica correta e houve melhora significativa na adesão ao tratamento, totalizando $87,5 \%(p=0,0188)$.

Na primeira avaliação 25 pacientes apresentavam ACT $<20$ e, após os três meses de seguimento, apenas 12 pacientes mantiveram o ACT <20.

Ao final das três avaliações 13 (32,5\%) pacientes foram classificados com asma grave resistente ao tratamento (AGRT), segundo critérios ATS ${ }^{7}$, após extensiva investigação, verificada adesão ao tratamento, corrigida técnica inalatória quando necessário, e tratamento das comorbidades encontradas (refluxo gastroesofágico, sinusopatia, rinite e parasitose intestinal). Apenas um paciente classificado com AGRT apresentava escore ACT $>20$, porém apresentava obstrução do fluxo de vias aéreas (FEV1<80\%) pósbroncodilatador.

Na tabela 2 estão os dados comparativos entre os dois grupos, dos quais apenas o escore do ACT e número de exacerbações apresentam diferenças estatisticamente significantes. 
Tabela 1: Análise comparativa de dados demográficos e clínicos dos pacientes com asma grave resistente ao tratamento $(\mathrm{N}=13)$ e asma grave controlada $(\mathrm{N}=27)$.

\begin{tabular}{|c|c|c|c|}
\hline Variáveis & AGRT & $\begin{array}{l}\text { Asma grave } \\
\text { controlada }\end{array}$ & Valor de $p$ \\
\hline Idade em anos - média (DP) & $12,45(2,73)$ & $12,9(2,9)$ & 0,610 \\
\hline Sexo masculino & $69,2 \%$ & $59,2 \%$ & 0,730 \\
\hline $\begin{array}{l}\text { Idade do início dos sintomas } \\
\text { em meses - média (DP) }\end{array}$ & $12,5(2,7)$ & $12,9(2,9)$ & 0,583 \\
\hline IMC* média Z escore (DP) & $0,9369(1,092)$ & $0,1837(1,507)$ & 0,116 \\
\hline Estatura média Z escore (DP) & $-0,200(0,9615)$ & $-0,351(1,023)$ & 0,658 \\
\hline Obesidade & $15,3 \%$ & $11,2 \%$ & 1,000 \\
\hline Contato com tabaco domiciliar & $23 \%$ & $22,2 \%$ & 1,000 \\
\hline Crise quase fatal pregressa & $38,4 \%$ & $44,4 \%$ & 1,000 \\
\hline Atopia*k & $92,3 \%$ & $92 \%$ & 1,000 \\
\hline Sinusopatia & $30,7 \%$ & $42,3 \%$ & 0,728 \\
\hline 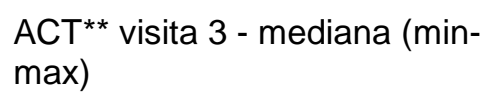 & $16(9-22)$ & $21(20-24)$ & $<0,0001$ \\
\hline $\begin{array}{l}\text { Número de exacerbações } \\
\text { durante seguimento do estudo } \\
\text { mediana (min-max) }\end{array}$ & $3(0-5)$ & $1(0-3)$ & 0,0023 \\
\hline Budesonida $800 \mathrm{mcg} / \mathrm{dia}$ & $92,3 \%$ & $70,4 \%$ & 0,226 \\
\hline Fluticasona $500 \mathrm{mcg} / \mathrm{dia}$ & $7,7 \%$ & $29,6 \%$ & 0,226 \\
\hline $\begin{array}{l}\text { Broncodilatador de longa } \\
\text { duração }\end{array}$ & $100 \%$ & $100 \%$ & \\
\hline Antagonista de leucotrieno & $69,2 \%$ & $48,1 \%$ & 0,311 \\
\hline Corticoide oral (visita1) & $7,8 \%$ & 0 & 0,325 \\
\hline Corticoide nasal & $100 \%$ & $92,6 \%$ & 0,550 \\
\hline Técnica correta (visita 1) & $79,9 \%$ & $85,2 \%$ & 0,662 \\
\hline Técnica correta (visita 3) & $100 \%$ & $100 \%$ & \\
\hline $\begin{array}{l}\text { Boa adesão tratamento } \\
\text { (visita1) }\end{array}$ & $69,2 \%$ & $59,2 \%$ & 0,730 \\
\hline $\begin{array}{l}\text { Boa adesão tratamento } \\
\text { (visita3) }\end{array}$ & $84,6 \%$ & $88,9 \%$ & 1,000 \\
\hline
\end{tabular}




\subsection{Avaliação funcional}

Em relação à avaliação funcional após os três meses de seguimento, treze pacientes $(32,5 \%)$ apresentaram espirometria normal. Nenhum paciente com distúrbio obstrutivo muito grave, apenas um com distúrbio ventilatório obstrutivo grave $(2,5 \%)$ e $10 \%$ apresentaram distúrbio obstrutivo moderadamente grave, $10 \%$ moderado e $45 \%$ leve. Não houve diferença estatisticamente significativa na classificação da gravidade do distúrbio ventilatório entre os dois grupos $(p=0,5636)$. Na pletismografia, $86 \%$ dos pacientes apresentaram valores de condutância abaixo do valor normal e a resposta ao broncodilatador foi mais expressiva através da medida da condutância ( $50 \%$ dos pacientes).

Não foram encontradas diferenças significantes nos parâmetros de função pulmonar nos dois grupos após os três meses de seguimento (tabela 2). 
Tabela 2: Parâmetros funcionais nos grupos de pacientes com asma grave resistente ao tratamento e asma grave controlada, na terceira visita:

\begin{tabular}{|c|c|c|c|}
\hline Parâmetros funcionais & $\begin{array}{c}\text { AGRT } \\
\text { Média (DP) }\end{array}$ & $\begin{array}{l}\text { Asma grave } \\
\text { controlada } \\
\text { Média (DP) }\end{array}$ & $\mathbf{P}$ \\
\hline ESPIROMETRIA & $\mathrm{N}=13$ & $\mathrm{~N}=27$ & \\
\hline VEF1 & $82,87 \%(24,35)$ & $89,57 \%(19,12)$ & 0,3489 \\
\hline CVF & $99,74(19,48)$ & $106,04 \%(17,54)$ & 0,3113 \\
\hline FEF25-75\% & $57,73 \%(30,03)$ & $65,36 \%(30,42)$ & 0,5066 \\
\hline VEF1/CV & $72,15 \%(13,26)$ & $74,04 \%(10,89)$ & 0,9654 \\
\hline PLETISMOGRAFIA & $\mathrm{N}=12$ & $\mathrm{~N}=20$ & \\
\hline CPT (\%pred) & $98,50 \%(13,24)$ & $104,3 \%(16,84)$ & 0,3938 \\
\hline VR (\%pred) & $130,4 \%(56,79)$ & $131,0 \%(68,49)$ & 0,9783 \\
\hline $\mathrm{VR} / \mathrm{CPT}$ & $23,92 \%(11,66)$ & $24,85 \%(11,10)$ & 0,8110 \\
\hline Resistência & $150,5 \%(74,34)$ & $139,3 \%(66,14)$ & 0,6465 \\
\hline Condutância & $44,75 \%(20,26)$ & $56,68 \%(31,88)$ & 0,2452 \\
\hline RESPOSTA BD & $\mathbf{N}(\%)$ & $\mathbf{N}(\%)$ & \\
\hline $\begin{array}{c}\text { VEF1 (14\% e } 265 \mathrm{ml} \text { em relação } \\
\text { ao basal)* }\end{array}$ & $8 / 13(61 \%)$ & 10/27 (37\%) & 0,1854 \\
\hline $\begin{array}{c}\text { \% incremento VEF1 pós-BD - } \\
\text { mediana (IIQ) }\end{array}$ & $14 \%(6,75 \%-19 \%)$ & $11 \%(1,25 \%-16,5 \%)$ & 0,242 \\
\hline $\begin{array}{c}\text { Condutância (55\% em relação ao } \\
\text { basal) * }\end{array}$ & $6 / 12(50 \%)$ & $11 / 20(55 \%)$ & 1,000 \\
\hline $\begin{array}{c}\% \text { incremento condutância pós-BD } \\
- \text { mediana (IIQ) }\end{array}$ & $60,2 \%(36,2 \%-93,9 \%)$ & $54,3 \%(21,7 \%-74,8 \%)$ & 0,533 \\
\hline \multicolumn{4}{|c|}{$\begin{array}{l}\text { Dados expressos como médias da porcentagem do previsto e desvio padrão. }{ }^{*} \text { Critério de } \\
\text { resposta ao broncodilatador de Bussamra } 2005^{62} \text { Siglas: VEF1: volume expiratório forçado no } \\
\text { primeiro segundo, CVF: capacidade vital forçada, VEF1/CV: relação entre volume expiratório } \\
\text { forçado no primeiro segundo e capacidade vital lenta, FEF } 25-75 \% \text { :fluxo expiratório forçado entre } \\
25-75 \% \text { da manobra da CVF, CPT: capacidade pulmonar total, VR: volume residual, VR/CPT: } \\
\text { relação entre volume residual e capacidade pulmonar total, Raw: resistência, Gaw: condutância. } \\
\text { Utilizado teste Mann-Whitney e teste exato de Fisher. }\end{array}$} \\
\hline
\end{tabular}

\subsection{Marcadores inflamatórios séricos, FeNO e Escarro induzido:}

Não houve diferença estatisticamente significante entre os dois grupos em relação aos eosinófilos séricos ou lgE total (tabela 3). 
$\mathrm{Na}$ análise da fração exalada do Oxido Nítrico, 53\% dos pacientes apresentaram valor alto, pelos critérios ATS $2011^{18}, 32 \%$ intermediário e $15 \%$ baixo. Não houve diferença significante nas medidas de FeNO nos dois grupos de pacientes (tabela 3) nem entre as duas visitas (gráfico1).

A taxa de sucesso na coleta do escarro induzido foi de $70 \%$ em toda a amostra, compatível com o encontrado na literatura ${ }^{22}$. Apenas dois pacientes apresentaram queda de FEV1 >20\% sendo necessário interrupção da indução do escarro, em ambos houve melhora após receberem salbutamol spray.

Gráfico 1: Análise de correlação da FeNO (fração exalada de óxido nítrico) entre as visitas 1 e 3 no grupo de pacientes com asma grave não controlada (A) e asma grave controlada ( $B$ ).
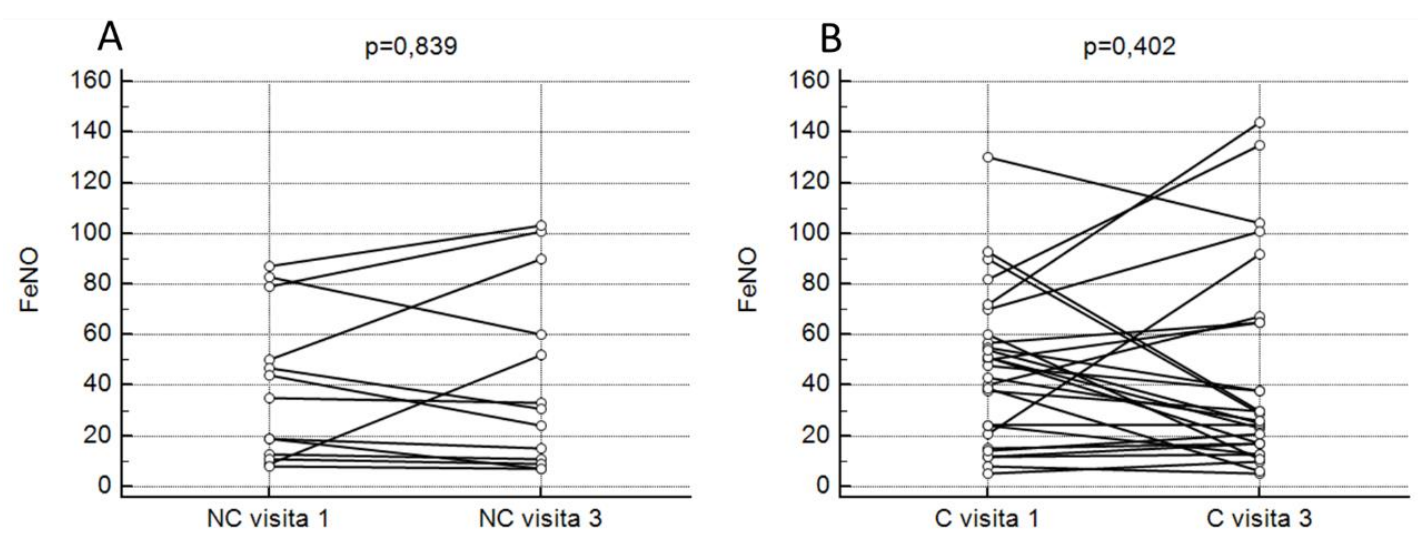

O grupo de pacientes com AGRT apresentou porcentagem proporcionalmente maior de neutrófilos no escarro comparado com o grupo de asma grave controlada, nas duas visitas. $(p<0,05)$ (gráfico 2), sem diferença no número total de células (tabela 3). 
Tabela 3: Parâmetros inflamatórios dos pacientes com asma grave resistente ao tratamento (AGRT) e asma grave controlada:

\begin{tabular}{lcccc}
\hline \multicolumn{1}{c}{ Variáveis } & AGRT & $\begin{array}{c}\text { Asma grave } \\
\text { controlada }\end{array}$ & P \\
\hline Eosinófilos séricos $/ \mathrm{mm}^{3}$ & $533,9(96,2-2.202,9)$ & $566,1(62,5-1.490)$ & 0,659 \\
IgE sérico UI/ml & $811,0(4,0-4.740,0)$ & $1.120,0(39,0-5.430,0)$ & 0,465 \\
FeNO (ppb) & $31,0(7,0-103,0)$ & $26,0(5,0-144,0)$ & 0,851 \\
\hline Escarro & & & \\
\hline Células totais $\times 10^{6}$ visita1 & $1,86(0,3-5,0)$ & $1,40(0,1-13,2)$ & 0,577 \\
\hline \% Eosinófilos visita 1 & $14,1 \%(0,4-65,2)$ & $20,7 \%(2,8-92,8)$ & 0,280 \\
\% Neutrófilos visita 1 & $43,6 \%(4,2-87,6)$ & $17,4 \%(3,4-67,3)$ & 0,037 \\
Células totais x10 visita3 & $3,60(1,2-6,6)$ & $0,84(0,28-2,02)$ & 0,075 \\
\% Eosinófilos visita 3 & $3,48 \%(0-66,67)$ & $4,4 \%(0-65,4)$ & 0,936 \\
\% Neutrófilos visita 3 & $44,68 \%(7,6-74,5)$ & $9,09 \%(0-57,4)$ & $\mathbf{0 , 0 0 9}$ \\
\hline
\end{tabular}

Valores expressos em medianas (mínimo e máximo), valores escarro em mediana da porcentagem da contagem de células totais. FeNO: fração exalada de óxido nítrico. Teste de Mann-Whitney.

Gráfico 2: Comparação entre porcentagem de neutrófilos no escarro induzido na visita 1 (A) e visita 3 (B) entre os grupos de asma grave controlada e asma grave resistente ao tratamento (AGRT).
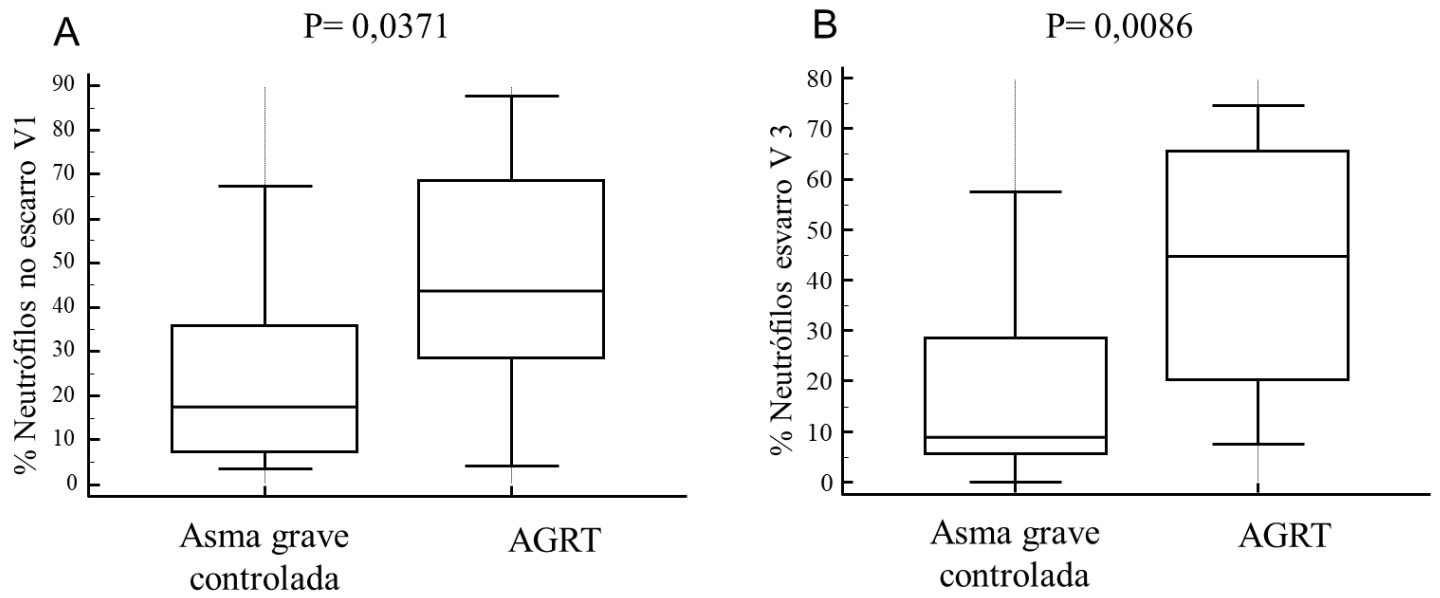

Quando comparados retrospectivamente em relação à classificação do escarro, houve diferença quanto ao escarro eosinofílico na primeira visita, $90 \%$ no grupo de asma grave controlada versus $50 \%$ no grupo de AGRT $(p<0,05)$ 
(tabela 5). Houve uma tendência de maior classificação do escarro neutrofílico na terceira visita no grupo AGRT $(p=0,0556)$ (tabela 4).

Tabela 4: Classificação do escarro no grupo de pacientes com AGRT e asma grave controlada na primeira e terceira visita. ${ }^{24}$

\begin{tabular}{|c|c|c|c|c|c|c|}
\hline \multirow{2}{*}{ Classificação } & \multicolumn{3}{|c|}{ Visita 1} & \multicolumn{3}{|c|}{ Visita 3} \\
\hline & Controlados & AGRT & $\mathbf{p}$ & Controlados & AGRT & $\mathbf{P}$ \\
\hline $\begin{array}{c}\text { Eosinofilicos } \\
\text { (Eo }>2,5 \% \text { e } \\
\text { neutr } \leq 54 \% \text { ) }\end{array}$ & 18/20 (90\%) & $4 / 8(50 \%)$ & 0,0384 & $13 / 21(61,9 \%)$ & $3 / 7(42,8 \%)$ & 0,4184 \\
\hline $\begin{array}{l}\text { Neutrofílicos } \\
\text { (Eo } \leq 2,5 \% \text { e } \\
\text { neutr }>54 \%)\end{array}$ & $1 / 20(5 \%)$ & $1 / 8(12,5 \%)$ & 0,4974 & $0 / 21$ & $2 / 7(28,5 \%)$ & 0,0556 \\
\hline $\begin{array}{l}\text { Misto } \\
\text { (Eo }>2,5 \% \text { e } \\
\text { neutr }>54 \%)\end{array}$ & $1 / 20(5 \%)$ & 2/8 (25\%) & 0,1880 & $1 / 21(4,7 \%)$ & $1 / 7(14,3 \%)$ & 0,4444 \\
\hline $\begin{array}{l}\text { Paucigranulocitico } \\
\text { (Eo } \leq 2,5 \% \text { e } \\
\text { neutr } \leq 54 \% \text { ) }\end{array}$ & $0 / 20$ & $1 / 8(12,5 \%)$ & 0,2857 & $7 / 21(33,3 \%)$ & $1 / 7(14,3 \%)$ & 0,6334 \\
\hline Insuficiente & $7 / 27$ (25,9\%) & $5 / 13(38,4 \%)$ & 0,4760 & $6 / 27(22,3 \%)$ & $\begin{array}{c}6 / 13 \\
(46,1 \%)\end{array}$ & 0,1536 \\
\hline
\end{tabular}

Valores expressos em $\mathrm{n} / \mathrm{N}$ total (porcentagem) dos pacientes com amostra de escarro suficiente para análise. Teste exato de Fisher.

Avaliando as diferenças na porcentagem de eosinófilos e de neutrófilos entre visita 1 e visita 3, não houve diferença estatisticamente significante em nenhum dos grupos de pacientes. (Gráfico 3) 
Gráfico 3: Porcentagem de eosinófilos e neutrófilos entre visitas as 1 e 3 nos grupos de asma grave controlada e não controlada ou resistente ao tratamento
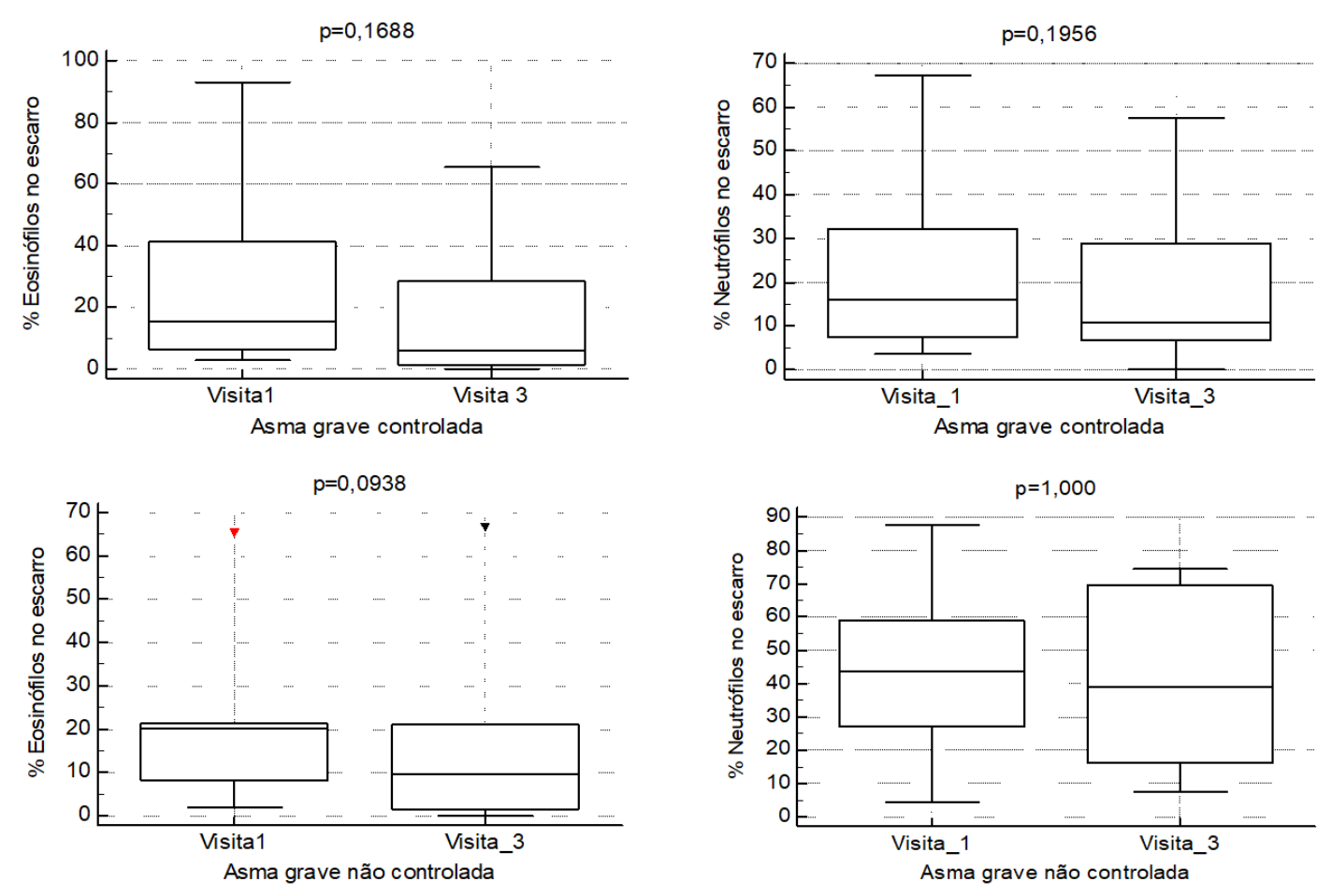

Não houve correlação estatisticamente significante entre \% eosinófilos $(p=0,488)$ ou $\%$ neutrófilos $(p=0,0871)$ no escarro e o questionário de controle ACT, nem com os parâmetros da função pulmonar. Assim como não houve entre FeNO e questionário de controle ACT $(p=0,792)$.

$\mathrm{Na}$ análise de comparação entre presença de diagnóstico de sinusopatia e presença de escarro neutrofílico, não foi encontrado significância estatística $(p=0,685)$.

Quando comparados os diferentes marcadores inflamatórios entre si, houve correlação estatisticamente significante entre a porcentagem de eosinófilos no escarro e FeNO na terceira visita (gráfico 4) e eosinófilos séricos e FeNO (grágico 5). Entretanto não foi encontrada correlação significante entre 
eosinófilos séricos e FEV1, ACT ou porcentagem de eosinófilos no escarro (gráfico 6).

Gráfico 4: Correlação entre \% de eosinófilos no escarro e medida da FeNO na terceira visita nos pacientes com asma grave. Correlação de Spearman r: 0,592 $95 \%$ IC $: 0,2697$ to 0,$7945 ; p=0,0009$.

$$
r=0,592 ; p=0,0009
$$

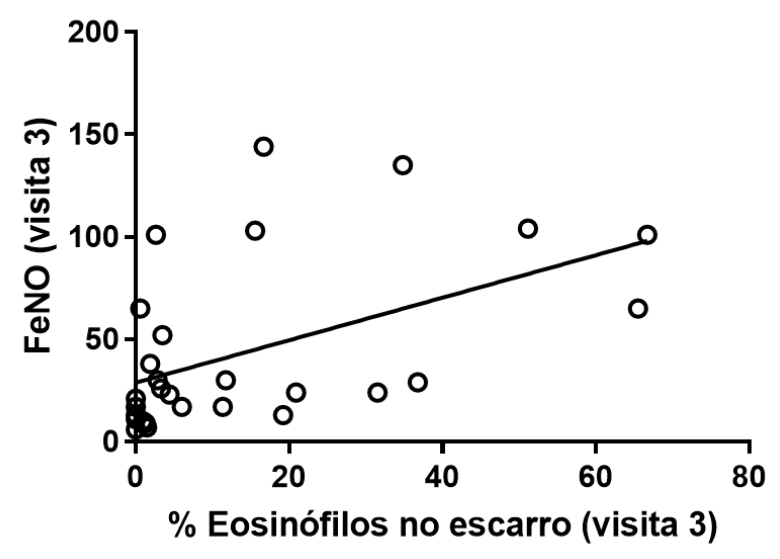

Gráfico 5: Correlação de Sperman entre FeNO na visita 1 e Eosinofilia sérica: $r=0,331 ; p=0,039$. FeNO em ppb e Eosinofilia em Eosinófilos séricos $/ \mathrm{mm}^{3}$

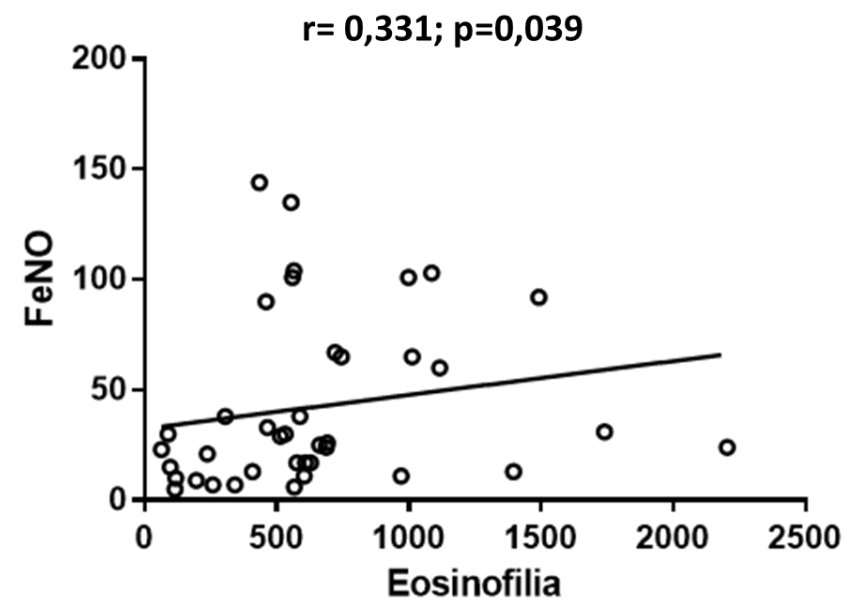


Gráfico 6: Correlação de Sperman da Eosinofilia sérica (eosinófilos $/ \mathrm{mm}^{3}$ ) com FEV1 (A) na terceira visita, Asthma control test (ACT) na terceira visita (B) e porcentagem de eosinófilos no escarro na visita 3 (C).
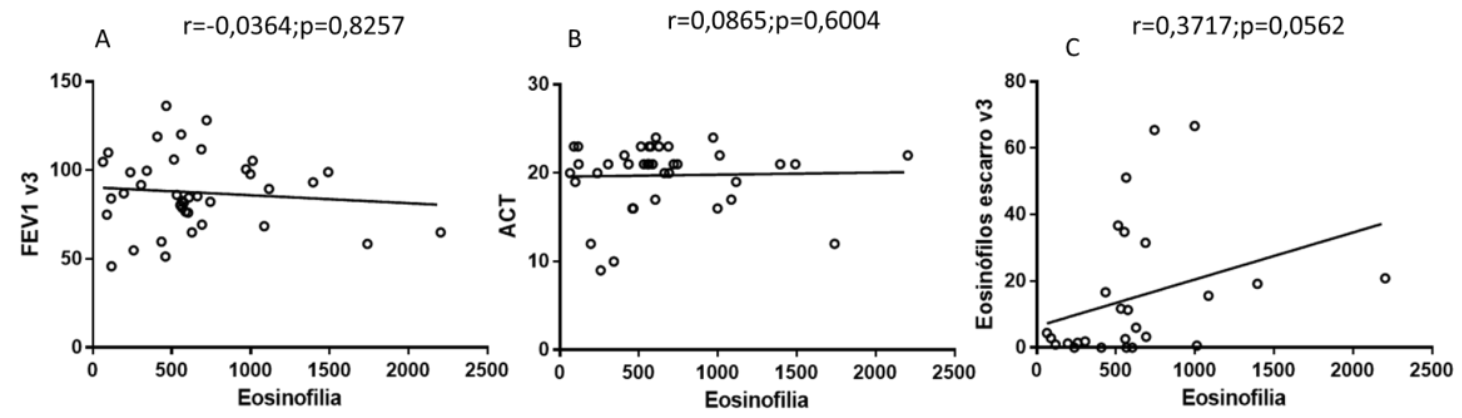

\subsection{Avaliação das Citocinas:}

$\mathrm{Na}$ pesquisa quantitativa de citocinas no escarro induzido foram encontradas no grupo de pacientes com asma controlada as seguintes citocinas com mediana acima do nível de detecção pelo método utilizado na visita 3: IL1ß, IL5, IL6, IL7, IL8, IL12, GM-CSF, G-CSF, MCP-1, INFy, TNFa, MIP-1b e IL17 e no grupo de asma grave resistente ao tratamento: IL1 $\beta$, IL2, IL5, IL6, IL7, IL8, IL10, IL13, GM-CSF, G-CSF, MCP-1, MIP-1b, INFy, IL17, TNFa. Com diferenças significativas nas medidas de IL10, GM-CSF, INFY e TNFa, com medianas maiores no grupo de AGRT (tabela 5). 
Tabela 5: Resultado das citocinas pesquisadas no escarro na terceira visita nos pacientes com asma grave resistente ao tratamento e asma grave controlada

\begin{tabular}{|c|c|c|c|}
\hline $\begin{array}{l}\text { Citocinas no } \\
\text { escarro }\end{array}$ & AGRT & Asma grave controlada & $\mathbf{P}$ \\
\hline 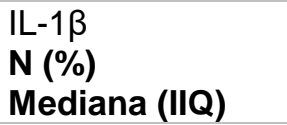 & $\begin{array}{c}8 / 9(88.9 \%) \\
863.91(184.9-1441,3)\end{array}$ & $\begin{array}{c}16 / 22(72.7 \%) \\
208.96(13.7-384.6)\end{array}$ & $\begin{array}{l}0.6395 \\
0.0515\end{array}$ \\
\hline $\begin{array}{l}\text { IL-4 } \\
\text { N (\%) } \\
\text { Mediana (IIQ) }\end{array}$ & $\begin{array}{l}3 / 9(33.4 \%) \\
\quad I(1-6.2)\end{array}$ & $\begin{array}{c}4 / 22(18.2 \%) \\
\text { I (I) }\end{array}$ & $\begin{array}{l}0.3841 \\
0.3889\end{array}$ \\
\hline $\begin{array}{l}\text { IL-5 } \\
\text { N (\%) } \\
\text { Mediana (IIQ) }\end{array}$ & $\begin{array}{c}7 / 9(77.8 \%) \\
16.00(7.7-28.3)\end{array}$ & $\begin{array}{l}14 / 22(63.6 \%) \\
13.25(I-32.8)\end{array}$ & $\begin{array}{l}0.6770 \\
0.5501\end{array}$ \\
\hline $\begin{array}{l}\text { IL-8 } \\
\text { N (\%) } \\
\text { Mediana (IIQ) }\end{array}$ & $\begin{array}{c}8 / 9(88.9 \%) \\
1955.0(320.2-6578.2)\end{array}$ & $\begin{array}{c}21 / 22(95.4 \%) \\
1247.1(498.5-1939.4)\end{array}$ & $\begin{array}{l}0.5032 \\
0.2400\end{array}$ \\
\hline $\begin{array}{l}\text { IL-13 } \\
\text { N (\%) } \\
\text { Mediana (IIQ) }\end{array}$ & $\begin{array}{c}7 / 9(77.7 \%) \\
23.21(5.4-68.6)\end{array}$ & $\begin{array}{l}\text { 9/22 (40.9\%) } \\
\text { I (I-27.4) }\end{array}$ & $\begin{array}{l}0.1134 \\
0.0918\end{array}$ \\
\hline $\begin{array}{l}\text { IFN-y } \\
\text { N (\%) } \\
\text { Mediana (IIQ) }\end{array}$ & $\begin{array}{c}8 / 9(88.9 \%) \\
654.97(230.8-1616.5)\end{array}$ & $\begin{array}{c}11 / 22(50 \%) \\
\mathbf{3 4 . 0 0}(\mathbf{l - 4 5 0 . 4 )}\end{array}$ & $\begin{array}{l}0.1012 \\
0.0264\end{array}$ \\
\hline $\begin{array}{l}\text { IL-17 } \\
\text { N (\%) } \\
\text { Mediana (IIQ) }\end{array}$ & $\begin{array}{c}8 / 9(98.9 \%) \\
74.160(32.8-233.5)\end{array}$ & $\begin{array}{c}18 / 22(81.8 \%) \\
47.98(25.5-98.8)\end{array}$ & $\begin{array}{l}1.0000 \\
0.3598\end{array}$ \\
\hline $\begin{array}{l}\text { TNF- } \alpha \\
\text { N (\%) } \\
\text { Mediana (IIQ) }\end{array}$ & $\begin{array}{c}8 / 9(98.9 \%) \\
54.03(38.5-233.5)\end{array}$ & $\begin{array}{l}14 / 22(63.6 \%) \\
\mathbf{1 5 . 7 3}(\mathrm{l}-\mathbf{4 5 . 6 )}\end{array}$ & $\begin{array}{l}0.2200 \\
\mathbf{0 . 0 1 1 3}\end{array}$ \\
\hline $\begin{array}{l}\text { IL-2 } \\
\text { N (\%) } \\
\text { Mediana (IIQ) }\end{array}$ & $\begin{array}{c}5 / 9(55.5 \%) \\
19.11(1-48.7)\end{array}$ & $\begin{array}{c}9 / 22(40.9 \%) \\
\text { I (I-14.9) }\end{array}$ & $\begin{array}{l}0.6227 \\
0.2434\end{array}$ \\
\hline $\begin{array}{l}\text { IL-6 } \\
\text { N (\%) } \\
\text { Mediana (IIQ) }\end{array}$ & $\begin{array}{c}8 / 9(88.9 \%) \\
215.52(167.0-1274.6)\end{array}$ & $\begin{array}{c}18 / 22(81.8 \%) \\
167.40(64.6-374.1)\end{array}$ & $\begin{array}{l}1.0000 \\
0.3266\end{array}$ \\
\hline $\begin{array}{l}\text { IL-7 } \\
\mathrm{N} \text { (\%) } \\
\text { Mediana (IIQ) }\end{array}$ & $\begin{array}{c}8 / 9(88.9 \%) \\
178.52(65.6-190.0)\end{array}$ & $\begin{array}{c}14 / 22(63.6 \%) \\
73.71(11.0-56.3)\end{array}$ & $\begin{array}{l}0.2200 \\
0.0675\end{array}$ \\
\hline $\begin{array}{l}\text { IL-10 } \\
\text { N (\%) } \\
\text { Mediana (IIQ) }\end{array}$ & $\begin{array}{c}7 / 9(77.8 \%) \\
35.83(11.0-56.3)\end{array}$ & $\begin{array}{l}\text { 10/22 (45.4\%) } \\
\text { I (I-32.0) }\end{array}$ & $\begin{array}{l}0.1317 \\
\mathbf{0 . 0 4 9 6}\end{array}$ \\
\hline $\begin{array}{l}\text { IL-12 } \\
\mathrm{N}(\%) \\
\text { Mediana (IIQ) }\end{array}$ & $\begin{array}{c}7 / 9(77.8 \%) \\
81.08(21.4-153.1)\end{array}$ & $\begin{array}{l}14 / 22(63.9 \%) \\
44.18(1-116.3)\end{array}$ & $\begin{array}{l}0.6770 \\
0.4150\end{array}$ \\
\hline $\begin{array}{l}\text { G-CSF } \\
\mathrm{N}(\%) \\
\text { Mediana (IIQ) }\end{array}$ & $\begin{array}{c}8 / 9(88.9 \%) \\
533.67(165.7-2794.9)\end{array}$ & $\begin{array}{c}20 / 22(90.9 \%) \\
362.40(231.1-1076.7)\end{array}$ & $\begin{array}{l}1.0000 \\
0.5863\end{array}$ \\
\hline $\begin{array}{l}\text { GM-CSF } \\
\text { N (\%) } \\
\text { Mediana (IIQ) }\end{array}$ & $\begin{array}{c}9 / 9(100 \%) \\
1630.9(1140.4-2023.5)\end{array}$ & $\begin{array}{c}18 / 22(81.8 \%) \\
\mathbf{4 8 7 . 5 0}(\mathbf{1 0 1 . 7 - 1 5 1 4 . 9 )}\end{array}$ & $\begin{array}{l}0.2952 \\
\mathbf{0 . 0 0 7 9}\end{array}$ \\
\hline $\begin{array}{l}\text { MCP-1 } \\
\mathrm{N} \text { (\%) } \\
\text { Mediana (IIQ) }\end{array}$ & $\begin{array}{c}9 / 9(100 \%) \\
333.80(138.3-713.0)\end{array}$ & $\begin{array}{c}21 / 22(95.45 \%) \\
230.75(113.9-377.1)\end{array}$ & $\begin{array}{l}1.0000 \\
0.4798\end{array}$ \\
\hline $\begin{array}{l}\text { MIP-1b } \\
\text { N (\%) } \\
\text { Mediana (IIQ) }\end{array}$ & $\begin{array}{c}9 / 9(100 \%) \\
1100.0(383.4-2952.6)\end{array}$ & $\begin{array}{c}19 / 22(86.3 \%) \\
432.05(164.0-1891.8)\end{array}$ & $\begin{array}{l}0.5375 \\
0.1843\end{array}$ \\
\hline
\end{tabular}


$\mathrm{Na}$ análise de correlação entre as citocinas presentes no escarro coletado na visita 3 e controle da asma através do escore do ACT, houve correlação inversamente significativa com GM-CSF e TNF- a (gráfico 7).

Gráfico 7: Correlação de Spearman entre escore de ACT na visita 3 e quantidade das citocinas GM-CSF (A) e TNF- $\alpha$ (B) no escarro induzido.
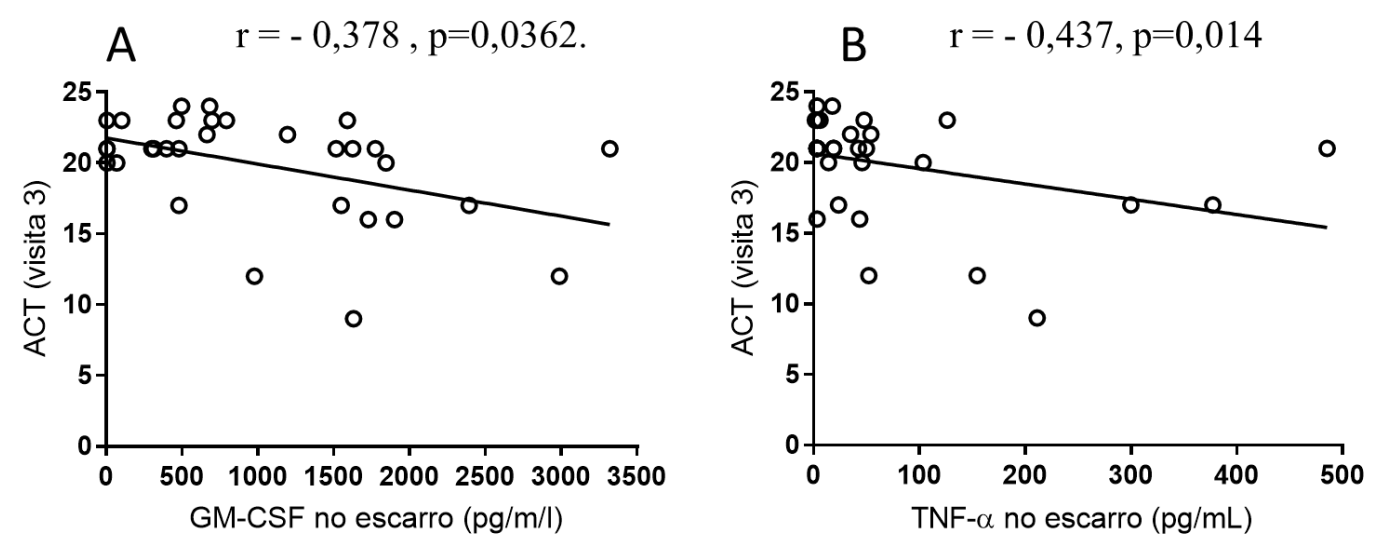

Não houve diferença significante entre a porcentagem de detecção das diferentes citocinas entre os escarros classificados como eosinofílicos e neutrofílicos. E na correlação entre eosinófilos e neutrófilos no escarro com as citocinas estudadas, houve correlação positiva e significativa entre a porcentagem de neutrófilos do escarro e IL-1 $\beta$ ( $r=0,43, p=0,0297 ;$ IC: 0,0484 a 0,709) e IL-8 ( $r=0,55, p=0,0040$, IC: 0,205 a 0,779) (gráfico 8). 
Gráfico 8: Correlação de Spearman entre porcentagem de neutrófilos no escarro na visita 3 e quantidade das citocinas IL-8 (A) e IL-1b (B) no escarro induzido.

A

$r=0,555 ; p=0,004$

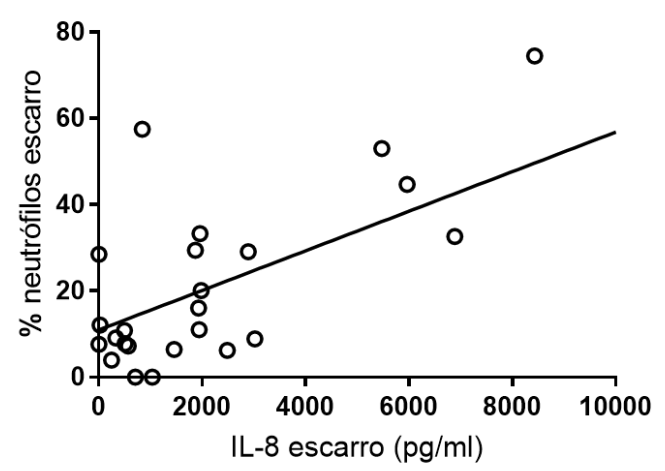

B

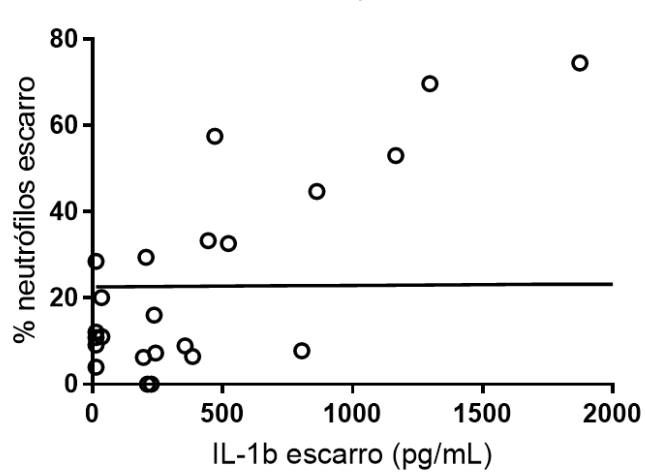


7 DISCUSSÃO 


\section{Discussão}

\subsection{Caracterização da casuística utilizada}

Neste estudo que investigou 40 crianças e adolescentes com diagnóstico de asma grave já em seguimento num hospital universitário por pelo menos 6 meses, foram identificados 13 pacientes $(32,5 \%)$ com asma grave resistente ao tratamento (AGRT) após extensiva investigação, verificação da adesão ao tratamento e identificação das comorbidades. As características clínicas e funcionais dos dois grupos foram semelhantes, porém os pacientes com AGRT tinham porcentagem significativamente maior de neutrófilos no escarro e medianas das citocinas IL-10, INF- $\gamma$, TNF- $\alpha$ e GM-CSF maiores do que o grupo controlado. Em adição, as citocinas TNF-a e GM-CSF foram associadas com pior controle da asma através do escore ACT.

Houve melhora significativa na adesão ao tratamento após o período de seguimento, o que resultou em uma porcentagem maior de pacientes com asma controlada, aproximadamente dois terços dos pacientes incluídos. Este fato deve ser atribuído ao seguimento próximo alcançado durante o período do protocolo.

Aproximadamente $30 \%$ de todos os pacientes apresentaram espirometria normal e menos de $20 \%$ apresentaram pletismografia normal, sendo a medida de condutância a mais frequentemente alterada. Não houve diferença significante nas medidas de espirometria e pletismografia entre os dois grupos. Dados semelhantes foram encontrado por Rodrigues et al em estudo com 
crianças asmáticas resistentes ao tratamento, levantando a hipótese de que esse grupo de paciente apresenta uma excessiva labilidade nos tônus broncomotor, o que explicaria a ausência de alterações significativas na função pulmonar em pacientes com sintomas frequentes ${ }^{65}$. Portanto, deve-se atentar para o fato de uma parcela dos pacientes pediátricos com asma grave não controlada apresentarem prova de função pulmonar normal e para a importância de realização de pletismografia nesse grupo de pacientes, por se mostrar mais sensível tanto na identificação de obstrução quanto na resposta ao broncodilatador.

As medidas da FeNO não conseguiram diferenciar os grupos de asma grave controlada e AGRT, reforçando as recomendações da ATS/ERS de que o FeNO não deve ser utilizado como parâmetro rotineiro de condução terapêutica desses pacientes ${ }^{18}$. Porém essa medida foi diretamente correlacionada com a porcentagem de eosinófilos presentes no escarro induzido. Esse achado difere do descrito por Lex et al, em que a FeNO não conseguiu prever eosinofila no escarro em crianças com asma grave de difícil controle ${ }^{16}$ e também por Saglani, et al. em adultos com asma grave ${ }^{66}$. Portanto, em que pese os dados conflitantes da literatura, os resultados do nosso estudo sugerem um possível papel da medida longitudinal da FeNO apenas em crianças com asma grave com padrão inflamatório eosinofílico e novos estudos de coorte mereceriam esclarecer este contexto.

Os dois grupos apresentaram predomínio de escarro eosinofílico nas duas avaliações, como já amplamente descrito na literatura em pacientes pediátricos com asma grave ${ }^{8}, 67$. Analisando retrospectivamente os dois grupos, os 
pacientes classificados como controlados após os três meses de seguimento, apresentavam maior taxa de escarro eosinofílico (90\%) comparados com o grupo AGRT (50\%) na primeira avaliação $(p=0,0384)$. Essa diferença não se manteve na terceira avaliação, pois houve aumento de escarro paucigranulocítico no grupo de asma grave controlada. Isso ocorreu provavelmente pela melhora da adesão ao tratamento e melhor resposta ao tratamento com corticoides inalatórios nesse grupo de pacientes.

Os pacientes com AGRT apresentaram porcentagem significativamente maior de neutrófilos no escarro nas duas avaliações $(p<0,05)$ e tendência a maior taxa de escarro neutrofílico na terceira avaliação $(p=0,0556)$. Esses achados diferem do encontrado por Bossley et al. em estudo em asma grave refratária ao tratamento na faixa etária pediátrica em que não foi identificado inflamação neutrofílica ${ }^{67}$, porém corrobora um recente estudo com crianças com asma grave resistente ao tratamento no sul do Brasil em que foi encontrado uma parcela considerável de escarro neutrofilico ${ }^{65}$. Existe, portanto, em nosso meio uma parcela de pacientes com asma grave não controlada com fenótipo inflamatório neutrofílico.

O padrão inflamatório do escarro em crianças com asma é variável ao longo do tempo ${ }^{25}$, e a presença de inflamação neutrofílica pode estar relacionada à infecção respiratória e ao uso de corticoides ${ }^{30}$. No entanto, no presente estudo, os escarros foram colhidos na ausência sinais e sintomas de infecção evidentes e os dois grupos receberam doses semelhantes de corticoides inalatórios e sem uso recente de corticoide sistêmico. Portanto, essa diferença entre os grupos sinaliza que a inflamação neutrofílica pode realmente ter um papel na AGRT de 
crianças e adolescentes, como anteriormente descrito por Gibson et al. em pacientes adultos com asma grave ${ }^{68}$ e recentemente em estudo que sinalizou 0 papel dos neutrófilos como sendo protetor em crianças com AGRT ${ }^{69}$.

Existe a hipótese de que, no contexto da asma, os neutrófilos são patogênicos e estão associados à doença mais grave ${ }^{30}$. Entretanto, isso tem se tornado cada vez mais incerto. Em alguns estudos o escarro neutrofílico não foi um marcador de gravidade da doença ${ }^{70}$. Além disso, existe a possibilidade dos neutrófilos atuarem de forma protetora e regulatória ${ }^{30}$. Pois, eles estão aumentados durante exacerbações induzidas por infecções ${ }^{17,30}$ e o uso de macrolídeos (azitromicina) como anti-inflamatório não tem sido bem-sucedido ${ }^{30}$. Finalmente, um recente estudo publicado por Andersson et al demostrou que 0 aumento de neutrófilos intraepiteliais em crianças com AGRT se correlacionou positivamente com \%FEV1 predito e também com melhor controle dos sintomas, a despeito do uso de menores doses de corticosteroides inalatórios, sugerindo um potencial papel benéfico dos neutrófilos na patogênese da asma grave ${ }^{69}$.

Em relação a avaliação das citocinas, foram encontradas no escarro dos dois grupos quantidades expressivas tanto de citocinas Th1 (IL-1 $\beta$, INF-y, TNFa, IL-12); Th2 (IL-5, IL-6, MCP-1, IL-13 no grupo AGRT) e Th17 (IL-17) Esses achados diferem de estudo que pesquisou citocinas em pacientes com asma grave refratária ao tratamento, e que não detectou presença de citocinas Th2 (IL4, IL5, IL13) e INFy ${ }^{67}$. Atribuímos isso ao fato de não termos utilizado DTT para análise das citocinas no sobrenadante do escarro. O uso habitual de DTT no processamento do escarro tem o objetivo de facilitar a contagem celular entretanto, pode interferir e minimizar a quantificação das diferentes citocinas 
inflamatórias ${ }^{64}$. Além disso, a presença concomitante de citocinas Th1 e Th2 corrobora o fato de que deve existir interação entre os mecanismos Th2 e nãoTh2 na patogênese da asma ${ }^{34}$.

As citocinas IL-10, INF- $y$, TNF- $\alpha$ e GM-CSF apresentaram medianas significativamente maiores no grupo de AGRT e o TNF- $\alpha$ e GM-CSF foram associados com pior controle da asma.

Demonstrou-se que a IL-10 está diminuída em doenças inflamatórias pulmonares, como fibrose cística e doenças pulmonares intersticiais ${ }^{48}$. Porém estudos na asma são contraditórios, com um aumento na expressão do RNAm da IL-10 em biopsias brônquicas, e aumento de IL-10 após sensibilização por alérgenos inalantes. Em contraste, a produção de IL-10 por macrófagos foi reportada estar deficiente na asma ${ }^{47}$. É possível também que a produção de IL10 pelas células T esteja desregulada na asma, com maior produção de IL-10 após a exposição aos alérgenos ambientais, mas ocorra uma redução da produção de IL-10 induzida pelos macrófagos ${ }^{48}$. Além disso, as funções efetoras da IL-10 podem estar reduzidas em pacientes asmáticos atópicos ${ }^{46}$. Esses achados poderiam explicar a maior quantidade de IL-10, uma citocina antiinflamatória, encontrada no grupo de asma não controlada. É certo que a IL-10 desempenha um papel na patogênese da asma, porém são necessários mais estudos para elucidar sua importância.

A quantidade significativamente maior de GM-CSF no grupo de pacientes com AGRT está de acordo com os dados da literatura, que suportam um potencial papel para a GM-CSF na asma e sugerem uma hiper-expressão do mesmo no escarro e mucosa brônquica, em particular na asma grave ${ }^{49}$. O GM- 
CSF foi correlacionado anteriormente com pior controle da asma ${ }^{49}$, corroborando os resultados do presente estudo. Os estudos com terapia anti GM-CSF foram realizados apenas em animais, mas apontam para um potencial alvo de novas terapias para a asma grave refrataria principalmente para o fenótipo inflamatório neutrofílico 49 .

O TNF- $\alpha$ também foi correlacionado com pior controle da asma em outros estudos que reportaram um aumento de TNF- $\alpha$ especificamente associado com fenótipo de AGRT ${ }^{41}, 42$. O TNFa é uma citocina pro-inflamatória Th1 que induz a inflamação das vias aéreas e hiperresponsividade brônquica, hipersecreção de muco e ativação de macrófagos ${ }^{34}$.

Este estudo apresenta como limitações: o tamanho da amostra e dificuldade na avaliação da adesão ao tratamento (realizado através da anamnese e controle de dispensação da medicação na farmácia). O tamanho da amostra, entretanto, é limitado devido a pequena porcentagem de crianças com STRA após início de seguimento e tratamento adequados. Esse fato aponta para necessidade de estudos multicêntricos neste grupo de pacientes. A verificação da adesão poderia ser melhor avaliada utilizando dispositivos eletrônicos de verificação de doses das medicações, entretanto tais dispositivos são dispendiosos e não disponíveis em nosso serviço.

A relevância deste estudo está na ampla investigação das células e citocinas inflamatórias no escarro induzido, método pouco invasivo e de fácil obtenção, em pacientes pediátricos com asma grave confrontando pacientes com AGRT com os que atingiram o controle pelos critérios da ATS/ERS ${ }^{7}$. Os resultados demonstram que as citocinas GM-CSF, TNF alfa, IL10 e INF-y podem 
desempenham papel importante no controle da asma grave e deveriam ser contempladas em futuros estudos em crianças com asma grave para confirmar esses achados em diferentes populações.

\subsection{Considerações finais}

Os achados corroboram com o fato de a asma grave ser uma doença de caráter extremamente heterogêneo, com diferentes fenótipos e da importância de se buscar marcadores inflamatórios para uma terapêutica mais individualizada objetivando o melhor controle da doença.

Estudos futuros devem investigar em longo prazo a evolução dessas crianças e adolescentes, avaliando o comportamento dos diferentes fenótipos inflamatórios ao longo do tempo e a evolução dos parâmetros funcionais desses pacientes, na tentativa de identificar a influência de marcadores clínicos e inflamatórios na transição da asma grave nas crianças e adolescentes para a asma grave na idade adulta e que podem ter efeito preventivo na morbimortalidade. 
8 CONCLUSÃO 


\section{Conclusão}

1. A Inflamação eosinofílica é predominante em crianças com asma grave, porém os neutrófilos e seus produtos parecem desempenhar um papel importante na AGRT.

2. A FeNO, nesse estudo, não demonstrou ser um biomarcador útil para diferenciar asma grave controlada de AGRT pediátrica. No entanto, parece ser útil para o seguimento dos pacientes com asma grave sabidamente eosinofílica.

3. No nosso estudo, de uma forma geral, não foi observado um comprometimento importante dos parâmetros funcionais nos pacientes com asma grave. Em adição, os parâmetros funcionais não parecem ser sensíveis para discriminar crianças e adolescentes com asma grave resistente ao tratamento, mesmo utilizando testes sensíveis de função pulmonar como os da pletismografia. Assim como não diferiu asma grave eosinofílica e neutrofílica.

4. A análise das citocinas no escarro nos pacientes com asma grave é complexa pelo possível envolvimento de várias delas na fisiopatologia da asma incluindo citocinas Th1, Th2 e TH17, porém, nesta casuística, o TNF-a e GM-CSF foram as que melhor se correlacionaram com pior controle da doença avaliado através do ACT.

Desta forma, a presença de neutrófilos no escarro e das citocinas IL10, INFY e, particularmente, GM-CSF e TNFa podem ter para um papel na resistência ao tratamento da asma grave em crianças e adolescentes. 
9 ANEXOS 


\section{Anexos}

ANEXO A: Aprovação da Comissão de Ética para Análise de Projetos de Pesquisa CAPPesq da Diretoria do Hospital das Clínicas da Faculdade de Medicina da Universidade de São Paulo
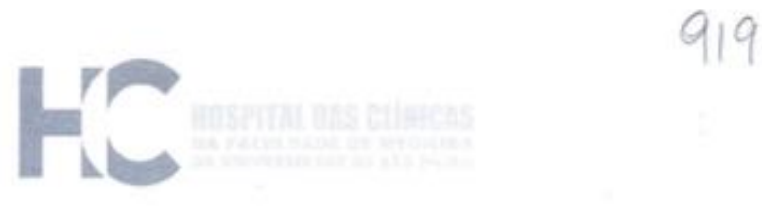

\section{APROVAÇÃO}

A Comissõo de Ética para Análise de Projetos de Pesquisa CAPPesa da Diretoria Clínica do Hospital das Clínicas da Faculdade de Medicina da Universidade de Sāo Paulo, em sessão de 02/02/2011. APROVOU o Protocolo de Pesquisa $n^{\circ}$ 0650/10, infitulado: FATORES CLÍNICOS E LABORATORIAIS ASSOCIADOS COM A ASMA GRAVE DE DIFÍCIL CONTROLE EM CRIANÇAS E ADOLESCENTES" apresentado pelo Departamento de PEDIATRIA, inclusive o Termo de Consenfimento Livre e Esclarecido $3^{a}$ versão.

Cabe ao pesquisador elaborar e apresentar à CAPPesq. os relatórios parciais e final sobre a pesquisa (Resolução do Conselho Nacional de Saúde $n^{\circ} 196$, de 10/10/1996, inciso 1X.2, letra "C'7.

Consideraçōes do relator: Recomenda-se manter a opçāo de "risco baixo" no Termo de Consentimento Livre e Esclarecido apresentado.

Pesquisador (a) Responsóvel: Joaquim Carlos Rodrigues

Pesquisador (a) Executante: Miriam Cardoso Neves Eller

CAPPesq, 04 de Fevereiro de 2011

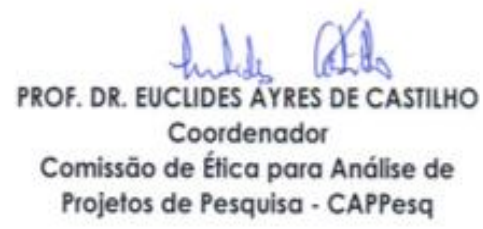

Comissáo de Etcica para Analise de Projetos de Pesquisa do HCFMUSP da Diretoria Clinica do Hospital das Clinicas da Faculdade de Medicina da Universidade de Sá Paulo Rua Ovidio Pires de Campos. 225. $5^{\circ}$ andar - CEP 05403010 - SA0 Paulo - SP Fone: 01130696442 Fax 01130696492 e-mait cappesq Bhenet usp br 
ANEXO B: Termo de consentimento

TERMO DE CONSENTIMENTO LIVRE E ESCLARECIDO

HOSPITAL DAS CLÍNICAS DA FACULDADE DE MEDICINA DA UNIVERSIDADE DE SÃO PAULOHCFMUSP

DADOS DE IDENTIFICAÇÃO DO SUJEITO DA PESQUISA OU RESPONSÁVEL LEGAL

1. NOME:

DOCUMENTO DE IDENTIDADE № : SEXO : .M $\square \mathrm{F} \square$

DATA NASCIMENTO: .........................

ENDEREÇO № APTO:

BAIRRO: CIDADE

CEP:. TELEFONE: DDD ( ...)

2.RESPONSÁVEL EGAL

NATUREZA (grau de parentesco, tutor, curador etc.)

DOCUMENTO DE IDENTIDADE : SEXO: $M \square F \square$

DATA NASCIMENTO.: ......................

ENDEREÇO:

№

APTO:

BAIRRO: CIDADE:

CEP: TELEFONE:DDD ).

\section{DADOS SOBRE A PESQUISA}

1. TÍTULO DO PROTOCOLO DE PESQUISA: Fatores clínicos e laboratoriais associados com a asma grave de difícil controle em crianças e adolescentes.

2. PESQUISADOR : Dr. Joaquim Carlos Rodrigues UNIDADE DO HCFMUSP: PNEUMOLOGIA PEDIÁTRICA - INSTITUTO DA CRIANÇA.

3. AVALIAÇÃO DO RISCO DA PESQUISA:

$\begin{array}{ll}\text { RISCO MÍNIMO } \square & \text { RISCO MÉDIO } \square \\ \text { RISCO BAIXO } \quad \square & \text { RISCO MAIOR } \square\end{array}$

4.DURAÇÃO DA PESQUISA : 6 meses 


\section{HOSPITAL DAS CLÍNICAS DA FACULDADE DE MEDICINA DA UNIVERSIDADE DE SÃO PAULO-HCFMUSP}

\section{OBJETIVOS:}

O objetivo deste estudo é identificar os fatores associados com o não controle da asma grave nas crianças e adolescentes em tratamento no Ambulatório de Pneumologia Pediátrica do Instituto da Criança- FMUSP.

\section{PROCEDIMENTOS:}

Coleta de sangue: será realizada coleta de sangue por punção periférica da veia do antebraço para análise laboratorial de fatores que podem afetar o controle da asma.

Espirometria: A espirometria é um exame indolor e rotineiro em todos os pacientes com asma. Durante esse teste a criança vai fazer uma série de sopros em um aparelho antes e após o uso do salbutamol spray no Laboratório de Prova de Função Pulmonar do Instituto da Criança. Este exame irá medir a capacidade respiratória da criança.

Teste alérgico: O Teste Alérgico é um exame simples e rápido, seu tempo de duração é de aproximadamente 20 minutos. São colocadas na pele do braço algumas gotas com substâncias que o indivíduo pode ser alérgico. Lancetas de plástico serão pressionadas superficialmente na pele em cima das gotas, podendo causar desconforto, mas sem causar sangramento. Após alguns minutos o médico irá ver quais substâncias causaram uma pequena reação alérgica na pele da criança.

Exames de imagem: Será realizada radiografia de tórax e tomografias de tórax e de seios da face com a menor radiação possível. Esses exames serão feitos para investigar sinusites e algumas alterações nos pulmões.

Avaliação do otorrinolaringologista: Os pacientes serão encaminhados para avaliação do otorrinolaringologista através de um exame chamado nasofibroscopia para investigação de alterações no nariz, adenóides e seios paranasais (por exemplo: sinusite). O exame é feito através de um fino aparelho flexível inserido no nariz do paciente com anestesia local em forma de gel, podendo causar leve desconforto.

Teste do escarro induzido: $O$ exame do escarro será realizado após três inalações com uma solução salgada para induzir a tosse e a expectoração. Existe o risco de essas inalações causarem uma crise de broncoespasmo na criança, mas se isso ocorrer o teste será interrompido e o médico irá medicar o paciente imediatamente. Este exame será realizado para o melhor conhecimento da doença pelos médicos. 
pHimpedânciometria: Os pacientes serão submetidos a pHimpedânciometria: exame realizado com fino aparelho capaz de medir a acidez do esôfago colocado através das narinas durante um período de internação de apenas 24 horas. Durante este período o acompanhante do paciente irá anotar os horários de alimentação, sintomas e posição da criança. Esse exame será realizado para pesquisa de refluxo gastroesofágico e posterior tratamento do paciente se necessário.

Broncoscopia com lavado broncoalveolar e biópsia brônquica: A broncoscopia será realizada nos pacientes diagnosticados com asma grave resistente ao tratamento (AGRT) por meio de um aparelho chamado broncoscópio. O broncoscópio é um fino tubo flexível que será colocado dentro dos brônquios do paciente através das narinas possibilitando a visualização direta e coleta de material do pulmão para exames. O exame será realizado sob anestesia geral. O lavado broncoalveolar é feito através da colocação de soro fisiológico pré-aquecida nos brônquios e sua imediata retirada por aspiração. A biopsia brônquica é feita com uma pequena pinça que passa por dentro do aparelho da broncoscopia e retira um pequeno fragmento da parede do bronquio do pulmão para estudo. Apesar de ser um procedimento sabidamente seguro em crianças, existem alguns riscos como sangramento e pneumotórax (escape de ar de dentro do pulmão para dentro do tórax podendo comprimir o pulmão e prejudicando a respiração) e riscos decorrentes da anestesia como alteração do ritmo cardíaco e depressão da função respiratória. No momento do exame os médicos terão acesso a medicamentos e equipamentos se houver alguma emergência e se necessário, o paciente ficará internado no Instituto da Criança aos cuidados do médico responsável pela pesquisa. Este exame não será realizado em todos os pacientes, apenas naqueles com asma grave não controlada com tratamento proposto, para melhor conhecimento da doença.

\section{BENEFÍCIOS:}

Os benefícios deste estudo serão a identificação de fatores associados ao não controle da asma, possivelmente tratáveis, e ao melhor conhecimento da doença para busca de novas formas de tratamento.

\section{GARANTIA DE ACESSO:}

Em qualquer etapa do estudo, você terá acesso aos profissionais responsáveis pela pesquisa para esclarecimento de eventuais dúvidas. O principal investigador é o Dr Joaquim C. Rodrigues que pode ser encontrado no Instituto da Criança HC-FMUSP. Se você tiver alguma consideração ou dúvida sobre a ética da pesquisa, entre em contato com o Comitê de Ética em Pesquisa (CEP) - Rua Ovídio Pires de Campos, 225 - $5^{\circ}$ andar - tel: 3069-6442 ramais 16, 17, 18 ou 20, FAX: 3069-6442 ramal 26 - E-mail: cappesq@hcnet.usp.br

É garantida a liberdade da retirada de consentimento a qualquer momento e deixar de participar do estudo, sem qualquer prejuízo à continuidade de seu tratamento na Instituição.

\section{DIREITOS DOS PACIENTES:}

As informações obtidas serão analisadas em conjunto com outros pacientes, não sendo divulgada a identificação de nenhum paciente. Os pacientes e seus responsáveis têm o 
direito de serem mantidos atualizados sobre os resultados parciais das pesquisas, quando em estudos abertos, ou de resultados que sejam do conhecimento dos pesquisadores. Os pesquisadores têm o compromisso de utilizar os dados e o material coletado somente para esta pesquisa.

\section{DESPESAS E COMPESAÇÕES:}

Não há despesas pessoais para o participante em qualquer fase do estudo, incluindo exames e consultas. Também não há compensação financeira relacionada à sua participação. Se existir qualquer despesa adicional, ela será absorvida pelo orçamento da pesquisa.

Acredito ter sido suficientemente informado a respeito das informações que li ou que foram lidas para mim, descrevendo o estudo: Fatores clínicos e laboratoriais associados com a asma grave de difícil controle em crianças e adolescentes.

Eu discuti com os pesquisadores sobre a minha decisão em participar nesse estudo. Ficaram claros para mim quais são os propósitos do estudo, os procedimentos a serem realizados, seus desconfortos, riscos e as garantias de confidencialidade e de esclarecimentos permanentes. Ficou claro também que minha participação é isenta de despesas e que tenho garantia do acesso a tratamento hospitalar quando houver alguma intercorrência nos procedimentos referentes ao protocolo da pesquisa. Concordo voluntariamente em participar deste estudo e poderei retirar o meu consentimento a qualquer momento, antes ou durante o mesmo, sem penalidades ou prejuízo ou perda de qualquer benefício que eu possa ter adquirido, ou no meu atendimento neste Serviço.

Assinatura do paciente/representante legal Data

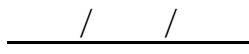

Assinatura da testemunha

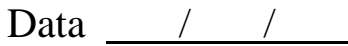

Para casos de pacientes menores de 18 anos, analfabetos, semi-analfabetos ou portadores de deficiência auditiva ou visual.

\section{(Somente para o responsável do projeto)}

Declaro que obtive de forma apropriada e voluntária o Consentimento Livre e Esclarecido deste paciente ou representante legal para a participação neste estudo. 
ANEXO C: Formulários utilizados na pesquisa

Protocolo ADC - Karina Vergani e Miriam Eller

Orientador : Dr Joaquim Carlos Rodrigues

\section{*VISITA 1}

Data:

Pront:

Nome:

Idade:

sexo:

\section{1) HPMA}

Idade início sintomas:

Idade do diagnóstico:

Início do tratamento:

Tratamento atual:

$\rightarrow$ Inalado:

$\rightarrow$ Oral: 
ANEXOS - 77

Equipoténcia estimada dos corticoides inalatónios para adultos."

\begin{tabular}{lccc}
\hline \multicolumn{1}{c}{$\begin{array}{c}\text { Corticoides } \\
\text { inalatorios }\end{array}$} & \multicolumn{3}{c}{ Dose diaria, pg } \\
\cline { 2 - 4 } & Baixa & Média & Alta \\
\hline Budesonida & $200-400$ & $>400-800$ & $>800-1.600$ \\
Dipropionato de beclometasona $^{\text {Ciclesonida }}$ & $200-500$ & $>500-1.000$ & $>1.000-2.000$ \\
Furoato de mometasona $^{*}$ & $80-160$ & $>160-320$ & $>320-1.280$ \\
Propionato de fluticasona & 200 & $\geq 400$ & $>800$ \\
\hline
\end{tabular}

'Comparaçóes baseadas em dados de eficacia. 'Pacientes em uso de altas doses, exceto por curtos periodos de tempo, devem ser encaminhados a especialista para considerar associaçóes alternativas de drogas controladoras. As doses maximas recomendadas sáo arbitrarias, mas o uso prolonga do esta associado ao aumento do risco de efeitos sistémicos. 'Dose diaria unica.

\section{Equipotencia estimada dos corticoides inalatóios para criangas maiores de cinco anos."}

\begin{tabular}{|c|c|c|c|}
\hline \multirow{2}{*}{$\begin{array}{l}\text { Corticoides } \\
\text { inalatorios }\end{array}$} & \multicolumn{3}{|c|}{ Dose diaria, pg } \\
\hline & Baixa & Média & Alta' \\
\hline Dipropionato de beclometasona & $100-200$ & $>200-400$ & $>400$ \\
\hline Budesonida & $100-200$ & $>200-400$ & $>400$ \\
\hline Budesonida nebulizada & $250-500$ & $>500-1.000$ & $>1.000$ \\
\hline Ciclesonida ${ }^{\circ}$ & $80-160$ & $>160-320$ & $>320-1.280$ \\
\hline Furoato de mometasona ${ }^{\circ}$ & 100 & $\geq 200$ & $\geq 400$ \\
\hline Propionato de fluticasona & $100-200$ & $>200-500$ & $>500$ \\
\hline
\end{tabular}

'Comparaçées baseadas em dados de eficacia. 'Pacientes em uso de altas doses, exceto por curtos periodos de tempo, deven ser encaminhados a especialista para considerar associaçóes alternativas de drogas controladoras. As doses maximas recomendadas sảo arbitrárias, mas o uso prolongado esta associado ao aumento do risco de efeitos sistênicos. "Dose diaria unica.

Adaptado de Global Initiative for Asthma - GINA [homepage on the Internet]. Bethesda: Global Initiative for Asthma. [cited 2011 Apr 1] Global Strategy for Asthma Management and Prevention, 2010. [Adobe Acrobat document, 119p.] Available from: http://www_ginasthma.org/pdf/GINA_Report_2010.pdf 
ANEXOS - 78

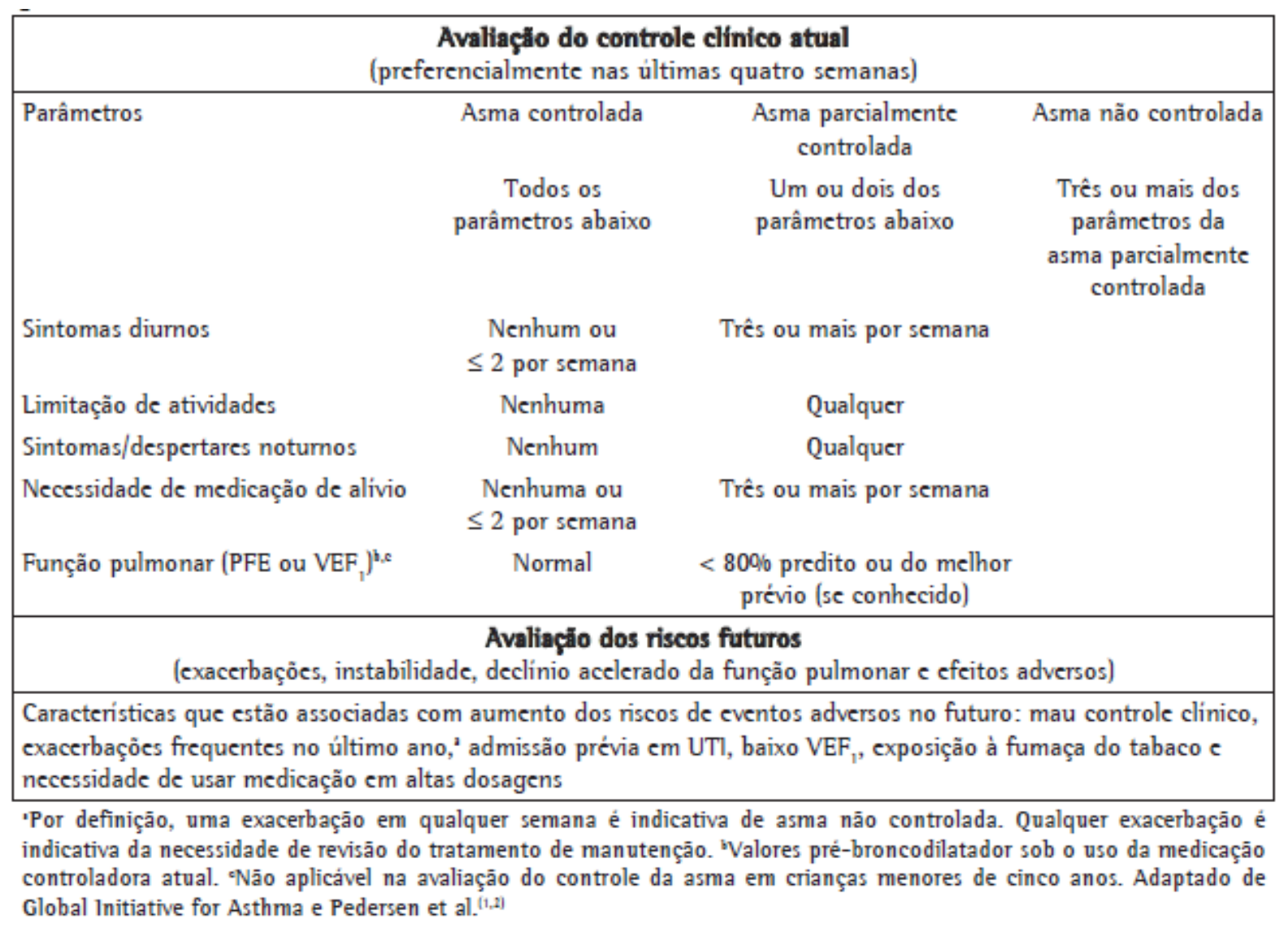

\begin{tabular}{|l|l|}
\hline Sintomas Diurnos & Limitação das Atividades \\
$\square$ Nenhum & $\square$ Nenhuma \\
$\square>2$ x/semana & $\square$ Qualquer \\
\hline Sintomas/despertares Noturnos & Necessidade Medicação Alívio \\
$\square$ Nenhum & $\square$ Nenhuma \\
$\square$ Qualquer & $\square<=2 x /$ semana \\
& $\square>2 x /$ semana \\
\hline
\end{tabular}


$\rightarrow$ Visitas ao PS (último ano):

$\mathrm{N}=$

$\rightarrow$ Internações (último ano):

$\mathrm{N}=$

$\rightarrow$ Crise asma quase-fatal (IOT/UTI) no passado:

$\mathrm{N}=$

$\rightarrow$ Uso de corticóide oral contínuo, ou quase contínuo (>50\% no ano):

$\square \operatorname{Sim}$

$\square$ Não

$\rightarrow$ Sintomas nasais

$\square \operatorname{Sim}$

$\square$ Não

$\rightarrow$ Sintomas RGE (pirose, epigastralgia, vômitos, dor abdominal)

$\square \operatorname{Sim}$

$\square$ Não

2) Exame Físico:

Peso:

E:

IMC:

SatO2 (AA):

Rino:

Oto:

Oro:

AP:

AC:

Abd:

Pele:

3) História Familiar

Asma $\rightarrow$ 
Rinite Alérgica $\rightarrow$

Dermatite Atópica $\rightarrow$

Alergia Alimentar $\rightarrow$

Tuberculose $\rightarrow$

\section{4) Ambiente}
$\square$ Casa alvenaria
$\square$ Casa tijolo
$\square$ Apto
$\square$ Pensão

Quantas pessoas habitam na moradia?

Quantas pessoas dormem no mesmo quarto?

Fumante na casa?

Quem?

Existe sinal de mofo na casa (paredes manchadas)?

Tem animais em casa?

Quais?

Técnica inalatória: $\square \mathrm{OK}$

Aderência: $\square$ esquece $>$ de $1 x$ por semana

$$
\square \text { esquece }<\text { de } 1 x \text { por semana }
$$

FeNO:

Pletismografia 


\section{Protocolo ADC - Karina Vergani e Miriam Eller}

Orientador : Dr Joaquim Carlos Rodrigues

\section{${ }^{*}$ VISITA 2*}

Data:

Pront:

Nome:

Idade:

sexo:

Evolução:

Tratamento atual:

$\rightarrow$ Inalado:

$\rightarrow$ Oral:

Técnica inalatória: $\square \mathrm{OK}$

Aderência: $\square$ esquece $>$ de $1 x$ por semana

$\square$ esquece $<$ de $1 \times$ por semana

Exames físico:

Exames:

1. Teste $\mathrm{Cl}$ no suor

2. Teste sacarina:

3. PPD: 
4. Prick test:

5. Hemograma:

6. $\lg \mathrm{E}: \quad \lg \mathrm{A}: \quad, \lg \mathrm{M}, \quad, \lg \mathrm{G}$ :

7. Sorologia toxocaríase (se eosinófilos $>500$ ):

8. Alfa 1-antitripsina:

9. PPF:

10. Phmetria com impedânciometria:

11. TC tórax:

12. TC seios da face:

13. Avaliação otorrinolaringológica:

Comorbidades:

Conduta: 


\section{Protocolo ADC - Karina Vergani e Miriam Eller}

Orientador : Dr Joaquim Carlos Rodrigues

\section{${ }^{*}$ VISITA $3^{*}$}

Data:

Pront:

Nome:

Idade:

sexo:

Evolução:

Tratamento atual:

$\rightarrow$ Inalado:

$\rightarrow$ Oral:

Técnica inalatória: $\square \mathrm{OK}$

Aderência: $\square$ esquece $>$ de $1 x$ por semana $\square$ esquece $<$ de $1 x$ por semana

Exames físico:

Realizado escarro induzido: Sim, Não FeNO:

Pletismografia:

Preenche critérios ATS/ERS: Sim, Não 
ANEXO D: Teste controle da asma (ACT)

Nas últimas quatro semanas:

Q1. A asma prejudicou suas atividades no trabalho, na escola ou em casa?
( ) Nenhuma vez
( )Poucas vezes
( )Algumas vezes
( )Maioria das vezes
( )Todo o tempo

Q2. Como está o controle da sua asma?
( ) Totalmente descontrolada
( )Pobremente controlada
( )Um pouco controlada
( )Bem controlada
( )Completamente controlada

Q3. Quantas vezes você teve falta de ar?
( )De jeito nenhum
( )Uma ou duas vezes por semana
( )Três a seis vezes por semana
( )Uma vez ao dia
( )Mais que uma vez ao dia

Q4. A asma acordou você à noite ou mais cedo que de costume?
( )De jeito nenhum
( )Uma ou duas vezes
( )Uma vez por semana
( )Duas ou três noites por semana
( )Quatro ou mais noites por semana

Q5. Quantas vezes você usou o remédio por inalação para alívio?
( )De jeito nenhum
( )Uma vez por semana ou menos
( )Poucas vezes por semana
( )Uma ou duas vezes por dia
( )Três ou mais vezes por dia 
O escore do questionário é calculado a partir da soma dos valores de cada questão, as quais valem de 1 a 5 pontos. As respostas que indicam maior controle da asma devem receber maior pontuação. Dessa forma, o escore do questionário varia entre 5 e 25 pontos: quanto maior o escore, mais controlada é a asma. 
ANEXO E: Formuário escarro induzido

\section{Pesquisa ADC - Pneumologia Pediátrica / Instituto da Criança \\ FORMULÁRIO DE REGISTRO DO ESCARRO INDUZIDO}

1. Nome:

2. Identificação:

3. Data:

4. Data de nascimento:

5. Peso $(\mathrm{Kg})$ :

6. Altura $(\mathrm{cm})$ :

7. Medicamentos nos últimos 30 dias:

8. Doenças respiratórias nos últimos 30 dias:

9. Doenças crônicas além de asma:

10. Espirometria: VEF1 (basal):

(L)/

(\%)

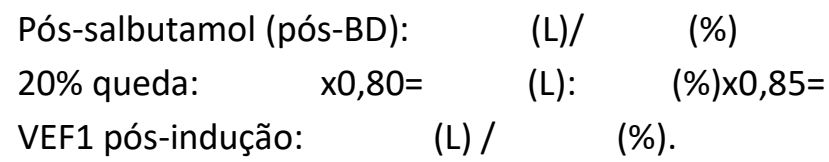

11. Indução escarro: (início) (término)

Nebulizações: Duração: min VEF1: (\%) CVF/VEF1:

Duração: $\min$ VEF1: (\%) CVF/VEF1:

Duração: min VEF1: (\%) CVF/VEF1:

Duração: min VEF1: (\%) CVF/VEF1:

Tempo total de nebulizações: $\quad \min$

Critérios de término do exame: ( ) desistência da criança

( ) queda persistente VEF1

( ) tempo total de $20 \mathrm{~min}$.

Sintomas durante e após a indução:

Observações: 


\section{Processamento do Escarro}

Tipo: Espontâneo( ) Induzido( )

Aparência: Mucóide ( ) Purulenta ( ) Muco-purulento ( )

Cor: incolor( ) branco( ) cinza( ) verde( ) amarelo( ) marrom( ) vermelho( )

\section{Processo escarro}

Número absoluto de células recuperadas:

Total contagem células: células $/ \mathrm{ml}$

Tempo do processamento:

Observador:

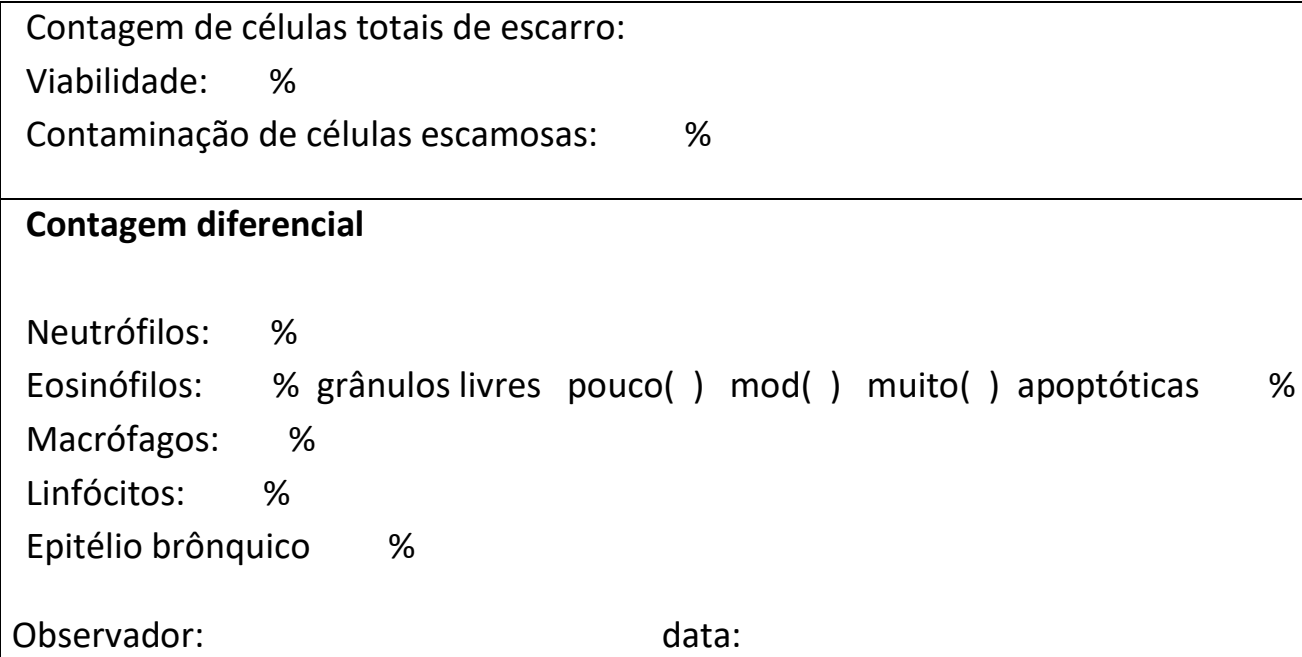




\section{ANEXO F: Processamento do Escarro}

PROCESSAMENTO DO ESCARRO

1) Separar o escarro da saliva, no tubo cônico de $12 \mathrm{ml}$

2) Resuspender o DTT com $1 \mathrm{ml}$ de PBS

3) Diluir o DTT :

$100 \mu \mathrm{l}$ de DTT a 1\% + $900 \mu \mathrm{l}$ de PBS. Preparar ate 4X o volume de PBS em, relação ao escarro

Geralmente se coloca o dobro Ex: $1 \mathrm{ml}$ de escarro $-2 \mathrm{~mL}$ de DTTc/PBS

4)Junte o DTT a $0,1 \%$ em PBS ao escarro puro

5)Agitar no vórtex

6) Banho Maria $\mathrm{T}=37^{\circ} \mathrm{C}$ e Tempo de $20 \mathrm{~min}$

7) Filtrar o escarro com o filtro azul

8) centrifugar na centrifuga grande $\mathrm{T}=4^{\circ} \mathrm{C}, 1800 \mathrm{RPM}$ ( = 790G) durante $10 \mathrm{~min}$

9) Separar o sobrenadante do botão celular ( aspirar com a pipeta)

10) Resuspensão do que sobrar

11) congelar a $-70^{\circ} \mathrm{Co}$ sobrenadante ( ver interleucinas)

12) Resuspensão do botão celular com $1 \mathrm{ml}$ de PBS puro

13) Contagem na camara de Neubauer_ $20 \mu \mathrm{l}$ da amostra $+20 \mu \mathrm{l}$ do azul de tripano

14)Contagem total das células na camara

Cálculo $=\mathrm{L} 1+\mathrm{L} 2+\mathrm{L} 3+\mathrm{L} 4 \times 10^{4}$

4

$\mathrm{L} 1+\mathrm{L} 2+\mathrm{L} 3+\mathrm{L} 4 \times 1 \times 2 \times 10^{4}$ 
Observações : número 1 equivale ao PBS que suspendeu o botão celular número $\mathbf{2}$ equivale a qtas partes vc coloca azul de tripano Colocar o resultado na potencia $10^{6}$

15) Pegar 2 tubinhos ependorfs

Tubo A- $200 \mu$ lda amostra e acrescentar 800de PBS

Tubo B $-400 \mu l$ da amostra e 600 de PBS

Agitar no vórtex

16) Cytospin : Colocar $100 \mu l$ da amostra diluída em cada poço da cytospin Load :1 Programa , 450 velocidade , durante $6 \mathrm{~min}$

17) Corante : 10 segundos no corante 1

10 segundos no corante 2

20 segundos no corante 3 
ANEXO G: Curvas de padronização das citocinas, obtidas a através do Bio-Plex Manager Software (Bio-Rad Laboratories, Hercules, CA)

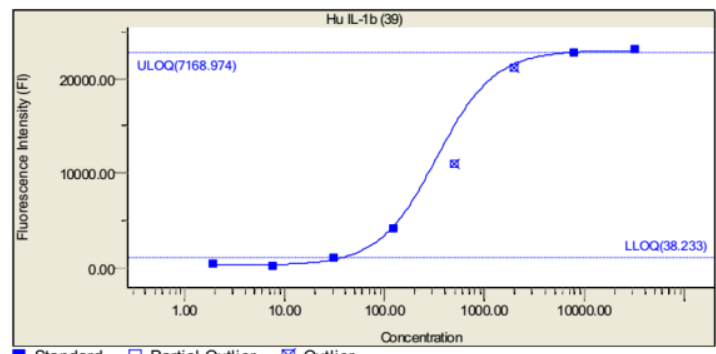

- Standard $\square$ Partial Outlier $\otimes$ Outlier

Regression Type: Logistic - 4PL

(23089.8 - 266.279) / (1+ (Conc / 335.659) $\left.)^{\wedge}-1.51636\right)$ FitProb $=0.0000$, ResVar. $=33.1778$

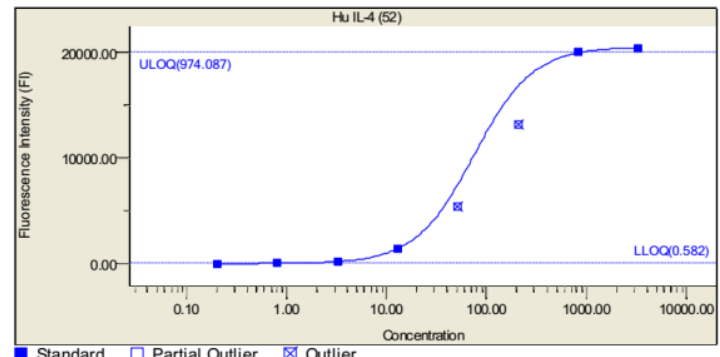

Regression $T$.

Std. Curve: $\mathrm{Fl}=33.7825+(20577-33.7825) /\left(1+(\text { Conc } / 75.909)^{\wedge}-1.48639\right)$ FitProb. $=0.0207$, ResVar. $=3.8752$

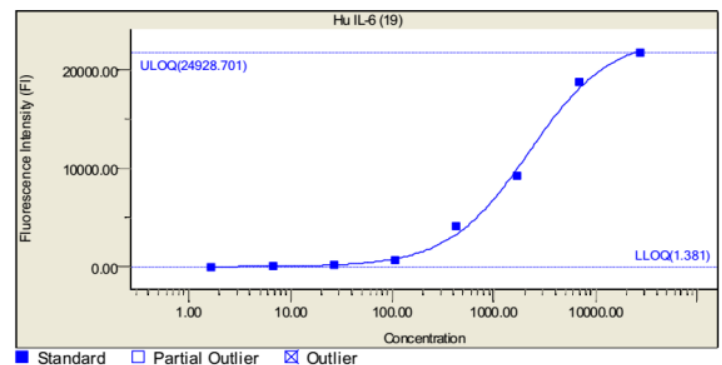

- Standard $\square$ Partial Outli

Regression Type: Logistic - 4PL

Std. Curve: $\mathrm{Fl}=21.2366+(23408.4-21.2366) /\left(1+(\text { Conc } / 2260.28)^{\wedge}-1.09608\right)$ FitProb. $=0.0000$, ResVar. $=7.8564$

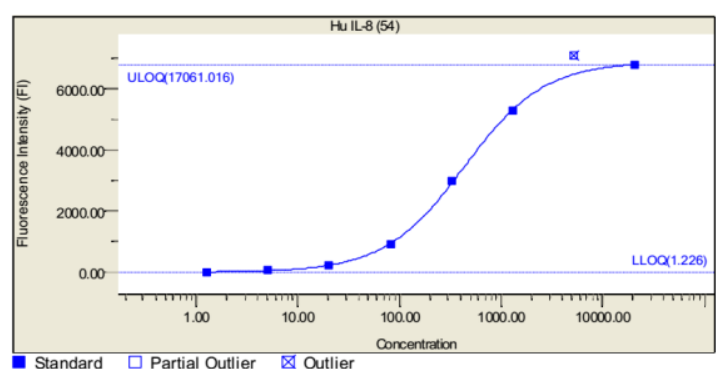

- Standard $\square$ Partial Outli
Regression Type: Logistic - $4 \mathrm{PL}$

Regression Type: Logistic $-4 \mathrm{PL}$
Std. Curve: $\mathrm{FI}=-1.64043+(6909+1.64043) /\left(1+(\text { Conc } / 440.11)^{\wedge}-1.10459\right)$ Std. Curve: $\mathrm{Fl}=-1.64043+16909+1.64$
FitProb. $=0.6788$, Res Var, $=0.5050$

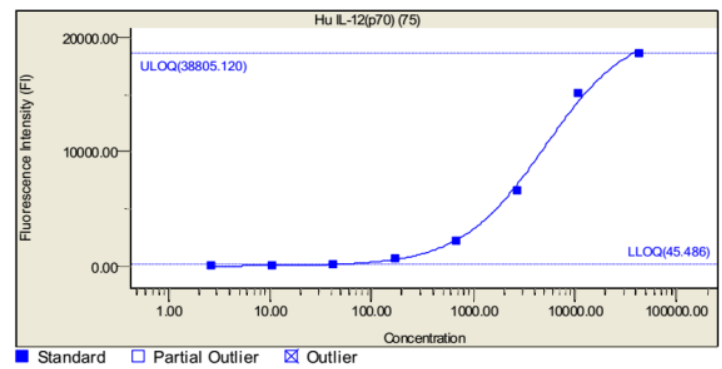
Regression Type: Logistic - 4PL

Regression Type: Logistic - 4PL

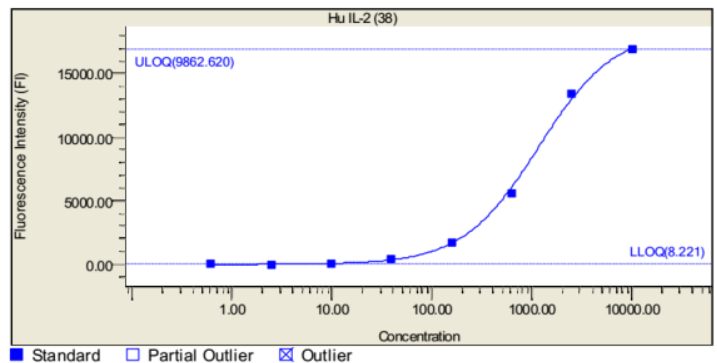

Partial Outlier $\otimes$ Outlier

Regression Type: Logistic - 4PL

(Conc / 1167.12) $)^{-1.15283)}$ FitProb $=0.0002$, ResVar. $=5.5964$

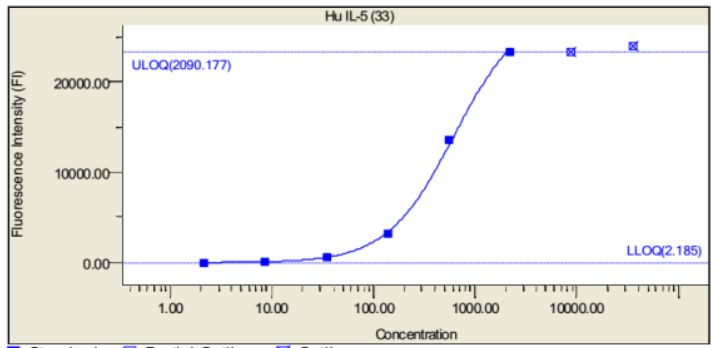

Regression Type: Logistic - OPL

Std. Curve: $\mathrm{Fl}=8.90773+(28193.1-8.90773) /\left(1+(\text { Conc } / 625.387)^{\wedge}-1.3257\right)$ FitProb. $=0.2443$, ResVar. $=1.4092$

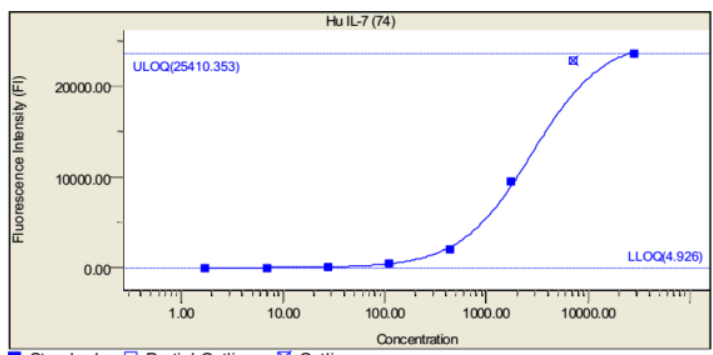

- Standard $\square$ Partial Outier $\otimes$ Outlier

Regression Type: Logistic - 4PL

Std. Curve: $\mathrm{Fl}=7.18801+(25227.3-7.18801) /\left(1+(\text { Conc } / 2837.8)^{\wedge}-1.24775\right)$ FitProb. $=0.0022$, ResVar. $=4.8500$

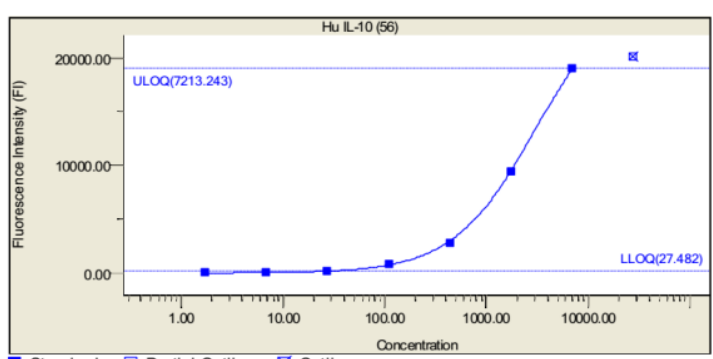

- Standard $\square$ Partial Outier ब Outlier

Regression Type: Logistic - 4PL

( 20.4773$) /\left(1+(\text { Conc / 3109.71) })^{\wedge}-1.06715\right)$ Fiprob. $=0.0012$, ResVar. $=5.2985$

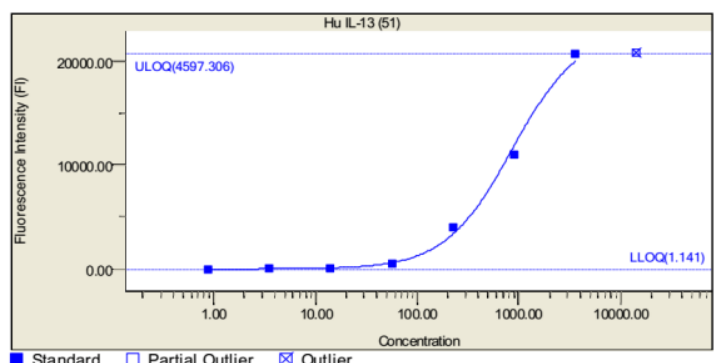

Regression Type: Logistic - 4PL

Std. Curve: $\mathrm{Fl}=12.6642+(23058.9-12.6642) /\left(1+(\text { Conc } / 867.396)^{\wedge}-1.32169\right)$ 
ANEXOS - 91

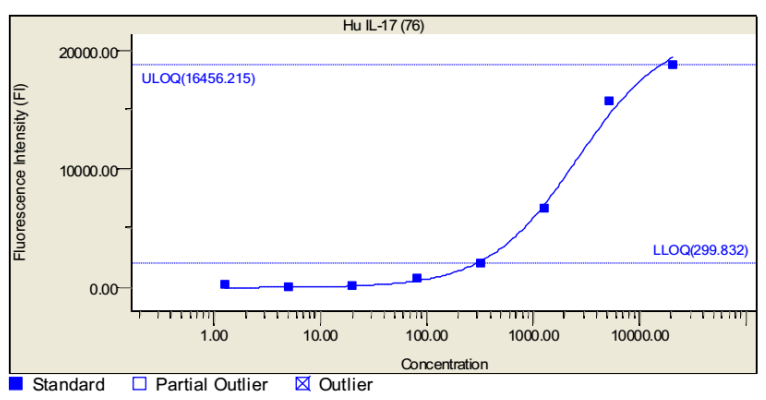

Regression Type: Logistic - 4PL

Std. Curve: $\mathrm{Fl}=-7.28143+(21647.1+7.28143) /(1+($ Conc / 2637.77)^-1.04085) FitProb. $=0.0000$, ResVar. $=53.6765$

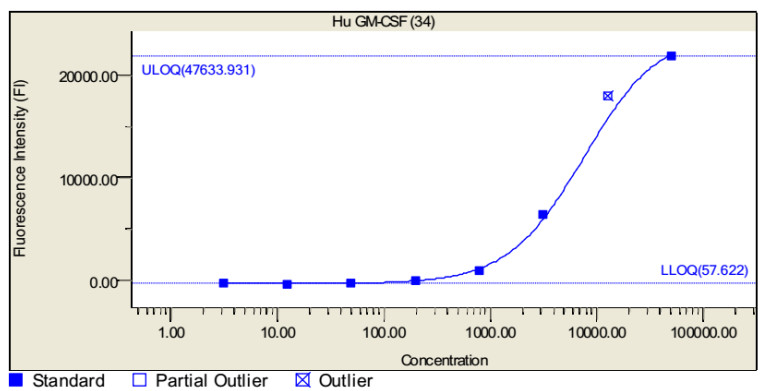

Standard $\square$ Partial Outlier

Regression Type: Logistic - Std. Curve: $\mathrm{Fl}=-338.254+(24392.4+338.254) /\left(1+(\text { Conc / 7642.16) })^{\wedge}-1.22149\right)$ FitProb. $=0.0000$, ResVar. $=16.6702$

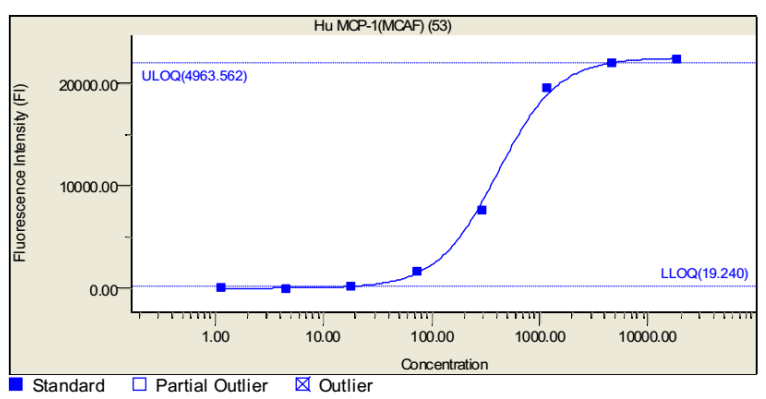

Regression Type: Logistic - 4PL

Std. Curve: $\mathrm{Fl}=0.898372+(22562.2-0.898372) /\left(1+(\text { Conc } / 413.173)^{\wedge}-1.5599\right)$ FitProb. $=0.0000$, ResVar. $=9.9171$

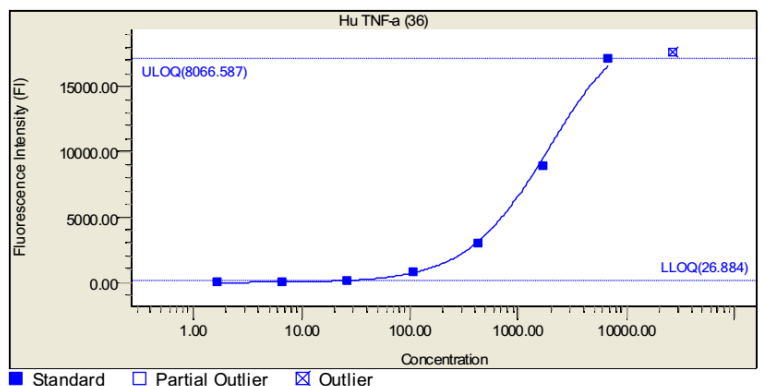

Standard $\square$ Partial Outli

Std. Curve: $\mathrm{Fl}=9.10376+(20640-9.10376) /\left(1+(\text { Conc } / 1957.51)^{\wedge}-1.13606\right)$

FitProb. $=0.0001$, ResVar. $=7.3014$

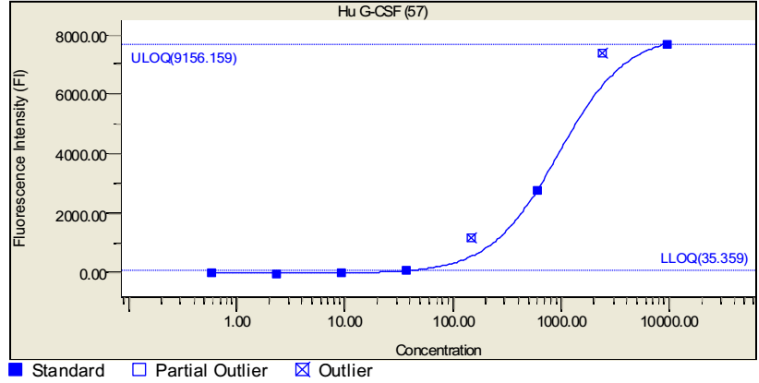

Regression Type: Logistic - 4PL

Std. Curve: $\mathrm{Fl}=-0.611008+(8023.89+0.611008) /\left(1+(\text { Conc } / 955.623)^{\wedge}-1.38676\right)$ FitProb. $=0.0000$, ResVar $=18.0858$

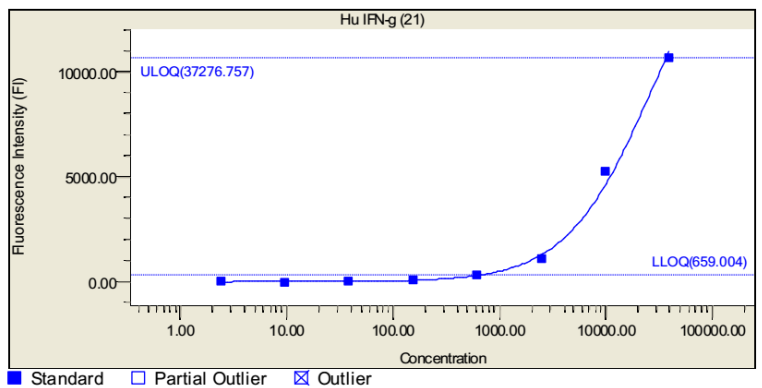
Regression Type: Logistic - 4PL

Std. Curve: $\mathrm{Fl}=1.72119+(18239.8-1.72119) /(1+($ Conc / 27230.3)^ 1.08249$)$ FitProb. $=0.0000$, ResVar. $=9.6162$

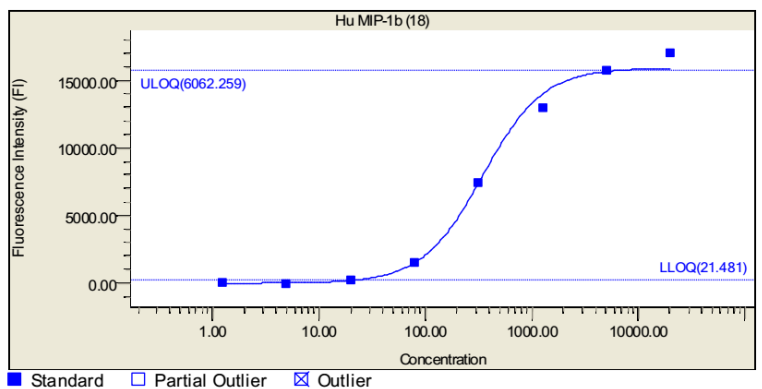
Regression Type: Logistic - 4PL

Std. Curve: $\mathrm{Fl}=18.0143+(15963.8-18.0143) /\left(1+(\text { Conc } / 352.84)^{\wedge}-1.53126\right)$ FitProb. $=0.0004$, ResVar. $=5.1703$ 
10 REFERÊNCIAS BIBLIOGRÁFICAS 


\section{Referências Bibliográficas}

1. Global Strategy for Asthma Management and Prevention.Global initiative for asthma (GINA);2012. Disponível em www.ginaasthma.org .

2.Cardoso, T. A.; Roncada, C.; Silva, E. R. D., et al. The impact of asthma in Brazil: a longitudinal analysis of data from a Brazilian national database system, J Bras Pneumol. 2017, 43, 163-168.

3.Solé, D.; Camelo-Nunes, I. C.; Wandalsen, G. F.; Mallozi, M. C. Asthma in children and adolescents in Brazil: contribution of the International Study of Asthma and Allergies in Childhood (ISAAC), Rev Paul Pediatr. 2014, 32, 114-125.

4.Louis, R. Severe asthma: how can we differentiate phenotypes?, Swiss Med Wkly. 2009, $139,274-277$.

5.Chung, K. F.; Godard, P.; Adelroth, E., et al. Difficult/therapy-resistant asthma: the need for an integrated approach to define clinical phenotypes, evaluate risk factors, understand pathophysiology and find novel therapies. ERS Task Force on Difficult/Therapy-Resistant Asthma. European Respiratory Society, Eur Respir J. 1999, $13,1198-1208$.

6.Kupczyk, M.; Wenzel, S. U.S. and European severe asthma cohorts: what can they teach us about severe asthma?, J Intern Med. 2012, 272, 121-132.

7.Chung, K. F.; Wenzel, S. E.; Brozek, J. L., et al. International ERS/ATS guidelines on definition, evaluation and treatment of severe asthma, Eur Respir J. 2014, 43, 343-373.

8.Saglani, S.; Lloyd, C. M. Eosinophils in the pathogenesis of paediatric severe asthma, Curr Opin Allergy Clin Immunol. 2014, 14, 143-148. 
9.Martin Alonso, A.; Saglani, S. Mechanisms Mediating Pediatric Severe Asthma and Potential Novel Therapies, Front Pediatr. 2017, 5, 154.

10.Global Strategy for Asthma Management and Prevention. Global initiative for asthma (GINA);2009. Disponível em www.ginaasthma.org.

11.Global Strategy for Asthma Management and Prevention. Global initiative for asthma (GINA);2017. Disponível em www.ginaasthma.org.

12.Bousquet, J.; Mantzouranis, E.; Cruz, A. A., et al. Uniform definition of asthma severity, control, and exacerbations: document presented for the World Health Organization Consultation on Severe Asthma, J Allergy Clin Immunol. 2010, 126, 926938.

13.Proceedings of the ATS workshop on refractory asthma: current understanding, recommendations, and unanswered questions. American Thoracic Society, Am J Respir Crit Care Med. 2000, 162, 2341-2351.

14.Fahy, J. V. Type 2 inflammation in asthma--present in most, absent in many, Nat Rev Immunol. 2015, 15, 57-65.

15.Anderson, G. P. Endotyping asthma: new insights into key pathogenic mechanisms in a complex, heterogeneous disease, Lancet. 2008, 372, 1107-1119.

16.Lex, C.; Ferreira, F.; Zacharasiewicz, A., et al. Airway eosinophilia in children with severe asthma: predictive values of noninvasive tests, Am J Respir Crit Care Med. 2006, $174,1286-1291$.

17.Fahy, J. V. Eosinophilic and neutrophilic inflammation in asthma: insights from clinical studies, Proc Am Thorac Soc. 2009, 6, 256-259.

18.Dweik, R. A.; Boggs, P. B.; Erzurum, S. C., et al. An official ATS clinical practice guideline: interpretation of exhaled nitric oxide levels (FENO) for clinical applications, Am J Respir Crit Care Med. 2011, 184, 602-615. 
19.Berry, M. A.; Shaw, D. E.; Green, R. H.; Brightling, C. E.; Wardlaw, A. J.; Pavord, I. D. The use of exhaled nitric oxide concentration to identify eosinophilic airway inflammation: an observational study in adults with asthma, Clin Exp Allergy. 2005, 35, $1175-1179$.

20.Shaw, D. E.; Berry, M. A.; Thomas, M., et al. The use of exhaled nitric oxide to guide asthma management: a randomized controlled trial, Am J Respir Crit Care Med. 2007, $176,231-237$.

21.Petsky, H. L.; Kew, K. M.; Chang, A. B. Exhaled nitric oxide levels to guide treatment for children with asthma, Cochrane Database Syst Rev. 2016, 11, CD011439.

22.Pizzichini, E.; Pizzichini, M. M.; Efthimiadis, A., et al. Indices of airway inflammation in induced sputum: reproducibility and validity of cell and fluid-phase measurements, $\mathrm{Am}$ J Respir Crit Care Med. 1996, 154, 308-317.

23.Gibson, P. G.; Grootendor, D. C.; Henry, R. L., et al. Sputum induction in children, Eur Respir J Suppl. 2002, 37, 44s-46s.

24.Lex, C.; Payne, D. N.; Zacharasiewicz, A., et al. Sputum induction in children with difficult asthma: safety, feasibility, and inflammatory cell pattern, Pediatr Pulmonol. 2005, 39, 318-324.

25.Fleming, L.; Tsartsali, L.; Wilson, N.; Regamey, N.; Bush, A. Sputum inflammatory phenotypes are not stable in children with asthma, Thorax. 2012, 67, 675-681.

26.Simpson, J. L.; Scott, R.; Boyle, M. J.; Gibson, P. G. Inflammatory subtypes in asthma: assessment and identification using induced sputum, Respirology. 2006, 11, 54-61.

27.Kelly, M. M.; Keatings, V.; Leigh, R., et al. Analysis of fluid-phase mediators, Eur Respir J Suppl. 2002, 37, 24s-39s. 
28.Efthimiadis, A.; Pizzichini, M. M.; Pizzichini, E.; Dolovich, J.; Hargreave, F. E. Induced sputum cell and fluid-phase indices of inflammation: comparison of treatment with dithiothreitol vs phosphate-buffered saline, Eur Respir J. 1997, 10, 1336-1340.

29.Efthimiadis, A.; Spanevello, A.; Hamid, Q., et al. Methods of sputum processing for cell counts, immunocytochemistry and in situ hybridisation, Eur Respir J Suppl. 2002, $37,19 \mathrm{~s}-23 \mathrm{~s}$.

30.Ciepiela, O.; Ostafin, M.; Demkow, U. Neutrophils in asthma--a review, Respir Physiol Neurobiol. 2015, 209, 13-16.

31.Jarjour, N. N.; Erzurum, S. C.; Bleecker, E. R., et al. Severe asthma: lessons learned from the National Heart, Lung, and Blood Institute Severe Asthma Research Program, Am J Respir Crit Care Med. 2012, 185, 356-362.

32.Simon, M. R.; Chinchilli, V. M.; Phillips, B. R., et al. Forced expiratory flow between $25 \%$ and $75 \%$ of vital capacity and FEV1/forced vital capacity ratio in relation to clinical and physiological parameters in asthmatic children with normal FEV1 values, J Allergy Clin Immunol. 2010, 126, 527-534.e521-528.

33.Stern, G.; de Jongste, J.; van der Valk, R., et al. Fluctuation phenotyping based on daily fraction of exhaled nitric oxide values in asthmatic children, J Allergy Clin Immunol. 2011, 128, 293-300.

34.Chung, K. F. Targeting the interleukin pathway in the treatment of asthma, Lancet. 2015, 386, 1086-1096.

35.Saglani, S.; Lui, S.; Ullmann, N., et al. IL-33 promotes airway remodeling in pediatric patients with severe steroid-resistant asthma, J Allergy Clin Immunol. 2013, 132, 676685.e613.

36.Lloyd, C. M.; Hawrylowicz, C. M. Regulatory T cells in asthma, Immunity. 2009, 31, 438-449. 
37.Mamessier, E.; Nieves, A.; Lorec, A. M., et al. T-cell activation during exacerbations: a longitudinal study in refractory asthma, Allergy. 2008, 63, 1202-1210.

38.Smyth, L. J.; Eustace, A.; Kolsum, U.; Blaikely, J.; Singh, D. Increased airway T regulatory cells in asthmatic subjects, Chest. 2010, 138, 905-912.

39.Yang, Y. L.; Pan, Y. Q.; He, B. S.; Zhong, T. Y. Regulatory T cells and Th1/Th2 in peripheral blood and their roles in asthmatic children, Transl Pediatr. 2013, 2, 27-33.

40.Saglani, S. Novel concepts in airway inflammation and remodelling in asthma.). 2015

41.Berry, M. A.; Hargadon, B.; Shelley, M., et al. Evidence of a role of tumor necrosis factor alpha in refractory asthma, $N$ Engl J Med. 2006, 354, 697-708.

42.Charrad, R.; Berraïes, A.; Hamdi, B.; Ammar, J.; Hamzaoui, K.; Hamzaoui, A. Antiinflammatory activity of IL-37 in asthmatic children: Correlation with inflammatory cytokines TNF- $\alpha$, IL- $\beta$, IL-6 and IL-17A, Immunobiology. 2016, 221, 182-187.

43.Ip, W. K.; Wong, C. K.; Lam, C. W. Interleukin (IL)-4 and IL-13 up-regulate monocyte chemoattractant protein-1 expression in human bronchial epithelial cells: involvement of p38 mitogen-activated protein kinase, extracellular signal-regulated kinase 1/2 and Janus kinase-2 but not c-Jun NH2-terminal kinase 1/2 signalling pathways, Clin Exp Immunol. 2006, 145, 162-172.

44.Chung, K. F. Asthma phenotyping: a necessity for improved therapeutic precision and new targeted therapies, J Intern Med. 2015.

45.Chung, K. F.; Barnes, P. J. Cytokines in asthma, Thorax. 1999, 54, 825-857.

46.Koulis, A.; Robinson, D. S. The anti-inflammatory effects of interleukin-10 in allergic disease, Clin Exp Allergy. 2000, 30, 747-750.

47.Gupta, A.; Dimeloe, S.; Richards, D. F., et al. Defective IL-10 expression and in vitro steroid-induced IL-17A in paediatric severe therapy-resistant asthma, Thorax. 2014, 69, 508-515. 
48.Kawano, H.; Kayama, H.; Nakama, T.; Hashimoto, T.; Umemoto, E.; Takeda, K. IL10-producing lung interstitial macrophages prevent neutrophilic asthma, Int Immunol. 2016.

49.Saha, S.; Doe, C.; Mistry, V., et al. Granulocyte-macrophage colony-stimulating factor expression in induced sputum and bronchial mucosa in asthma and COPD, Thorax. 2009, 64, 671-676.

50.Panousis, C.; Dhagat, U.; Edwards, K. M., et al. CSL311, a novel, potent, therapeutic monoclonal antibody for the treatment of diseases mediated by the common $\beta$ chain of the IL-3, GM-CSF and IL-5 receptors, MAbs. 2016, 8, 436-453.

51.Yamashita, N.; Tashimo, H.; Ishida, H., et al. Attenuation of airway hyperresponsiveness in a murine asthma model by neutralization of granulocytemacrophage colony-stimulating factor (GM-CSF), Cell Immunol. 2002, 219, 92-97.

52.Murray, L. A.; Syed, F.; Li, L.; Griswold, D. E.; Das, A. M. Role of chemokines in severe asthma, Curr Drug Targets. 2006, 7, 579-588.

53.Hinks, T.; Zhou, X.; Staples, K., et al. Multidimensional endotypes of asthma: topological data analysis of cross-sectional clinical, pathological, and immunological data, Lancet. 2015, 385 Suppl 1, S42.

54.Bush, A.; Saglani, S. Management of severe asthma in children, Lancet. 2010, 376, 814-825.

55.Roxo, J. P.; Ponte, E. V.; Ramos, D. C.; Pimentel, L.; D'Oliveira Júnior, A.; Cruz, A. A. [Portuguese-language version of the Asthma Control Test], J Bras Pneumol. 2010, 36, 159-166.

56.Bossley, C. J.; Fleming, L.; Ullmann, N., et al. Assessment of corticosteroid response in pediatric patients with severe asthma by using a multidomain approach, J Allergy Clin Immunol. 2016. 
57.Chatkin, J. M.; Cavalet-Blanco, D.; Scaglia, N. C.; Tonietto, R. G.; Wagner, M. B.; Fritscher, C. C. Compliance with maintenance treatment of asthma (ADERE study), $J$ Bras Pneumol. 2006, 32, 277-283.

58.Laszlo, G. Standardisation of lung function testing: helpful guidance from the ATS/ERS Task Force, Thorax. 2006, 61, 744-746.

59.Stocks, J.; Godfrey, S.; Beardsmore, C.; Bar-Yishay, E.; Castile, R.; Society, E. Plethysmographic measurements of lung volume and airway resistance. ERS/ATS Task Force on Standards for Infant Respiratory Function Testing. European Respiratory Society/ American Thoracic Society, Eur Respir J. 2001, 17, 302-312.

60.Quanjer, P. H.; Stanojevic, S.; Cole, T. J., et al. Multi-ethnic reference values for spirometry for the 3-95-yr age range: the global lung function 2012 equations, Eur Respir J. 2012, 40, 1324-1343.

61.Stocks, J.; Quanjer, P. H. Reference values for residual volume, functional residual capacity and total lung capacity. ATS Workshop on Lung Volume Measurements. Official Statement of The European Respiratory Society, Eur Respir J. 1995, 8, 492-506. 62.Bussamra, M. H.; Cukier, A.; Stelmach, R.; Rodrigues, J. C. Evaluation of the magnitude of the bronchodilator response in children and adolescents with asthma, Chest. $2005,127,530-535$.

63.Palomino, A. L.; Bussamra, M. H.; Saraiva-Romanholo, B. M.; Martins, M. A.; Nunes, M. o. P.; Rodrigues, J. C. [Induced sputum in children and adolescents with asthma: safety, clinical applicability and inflammatory cells aspects in stable patients and during exacerbation], J Pediatr (Rio J). 2005, 81, 216-224.

64.Woolhouse, I. S.; Bayley, D. L.; Stockley, R. A. Effect of sputum processing with dithiothreitol on the detection of inflammatory mediators in chronic bronchitis and bronchiectasis, Thorax. 2002, 57, 667-671. 
65.Rodrigues, A. M.; Roncada, C.; Santos, G., et al. Clinical characteristics of children and adolescents with severe therapy-resistant asthma in Brazil, J Bras Pneumol. 2015, 41, 343-350.

66.Saglani, S.; Bush, A. Asthma, atopy, and airway inflammation: what does it mean in practice?, Am J Respir Crit Care Med. 2008, 178, 437-438.

67.Bossley, C. J.; Fleming, L.; Gupta, A., et al. Pediatric severe asthma is characterized by eosinophilia and remodeling without $\mathrm{T}(\mathrm{H}) 2$ cytokines, J Allergy Clin Immunol. 2012, 129, 974-982.e913.

68.Gibson, P. G.; Simpson, J. L.; Saltos, N. Heterogeneity of airway inflammation in persistent asthma : evidence of neutrophilic inflammation and increased sputum interleukin-8, Chest. 2001, 119, 1329-1336.

69.Andersson, C. K.; Adams, A.; Nagakumar, P., et al. Intraepithelial neutrophils in pediatric severe asthma are associated with better lung function, J Allergy Clin Immunol. 2017, 139, 1819-1829.e1811.

70.Hinks, T. S.; Zhou, X.; Staples, K. J., et al. Innate and adaptive T cells in asthmatic patients: Relationship to severity and disease mechanisms, J Allergy Clin Immunol. 2015, 136, 323-333. 